\title{
Las bibliotecas en las estancias jesuíticas. El caso de Santa Catalina (Córdoba-Argentina)
}

\author{
Libraries in the Jesuit Stays. \\ The case of Santa Catalina (Córdoba-Argentina)
}

Silvana M. Lovay*

Resumen: El patrimonio librario de los antiguos jesuitas no se circunscribió únicamente a sus colegios, sino también a diversos y variados domicilios de su órbita organizativa, constituyéndose en bibliotecas menores. Como las del noviciado, convictorio, botica, reducciones $\mathrm{y}$, entre ellas, las estancias que solventaban los gastos de las actividades pastorales y educativas de los colegios. En el presente trabajo analizamos los libros de la estancia de Santa Catalina, que cubría los gastos de provincia y del noviciado de la Provincia Jesuítica del Paraguay. Con ello pretendemos rescatar este fondo a partir de la escasa información que brindan los inventarios de las Temporalidades para contribuir a reconstruir su legado cultural en este espacio particular.

Palabras clave: Bibliotecas. Provincia jesuítica del Paraguay. Estancia de Santa Catalina

\begin{abstract}
The libraries of the ancient Jesuits were not confined solely to their schools, but also to various and varied domiciles of their organizational orbit, being constituted in smaller libraries. Such as those of the novitiate, convict, apothecary, reductions and, among them, the stays that solved the expenses of the pastoral and educational activities of the schools. In the present work we analyze the books of the stay of Santa Catalina, that solved the expenses of province and of the novitiate of the Jesuit Province of Paraguay. With this we intend to rescue this fund based on the little information provided by the inventories of the Temporalities to help rebuild its cultural legacy in this particular space.
\end{abstract}

* CIECS-CONICET/UNC. Email: lovaysilvi@ hotmail.com.

166 Silvana M. Lovay. Las bibliotecas de las estancias jesuíticas... 166-200. 
Key words: Libraries. Jesuit Province of Paraguay. Estancia de Santa Catalina

Recibido: 6 de febrero de 2017.

Evaluado: 28 de abril de 2017. 


\section{Introducción}

Las estancias jesuíticas eran los medios económicos con los que contaban estos religiosos para desarrollar una educación gratuita y demás ministerios del Instituto. La formación de sus novicios y el constante perfeccionamiento intelectual de sus miembros quedó manifiesto en sus Constituciones (4:372 7) que establecían la creación de bibliotecas con personal escogido por los rectores. También en la Ratio Studiorum, al establecer las reglas del provincial (33), se menciona el tema y se profundiza, ya que se debía destinar una entrada anual para compra de libros. Incluso en la Regulae Praefecti Bibliothecae (1620) se establecen en 12 puntos las funciones del bibliotecario o prefecto de la biblioteca y del uso de la misma. No obstante la selección y organización de las bibliotecas supuso que algunos miembros de la Orden escribieran sobre un systema bibliothecae propio. Tal es el caso del P. Antonio Possevino, el más importante bibliógrafo del siglo XVI que propuso un aceptado sistema de clasificación, que se impuso en todos los centros jesuíticos. Le siguieron el P. Claude Clément (1635), Gabriel Cossart (1678) y su continuador Jean Garnier (1678), quienes fueron perfeccionando la técnica y el pensamiento biblioteconómico de la Compañía de Jesús (Miguel Alonso, 1998, p. 77-79).

De tal forma que se formó en Córdoba un importante fondo bibliográfico que fue lentamente adquirido por compra, donaciones de particulares y por la producción, no solo de sus propias imprentas, sino también de sus miembros, tanto americanos como europeos e incluso combinando ellos con autores indígenas que publicaban en la imprenta de las reducciones ${ }^{1}$. Varios documentos muestran que los procuradores a Europa, como los PP. Ferrufino (1636), Ojeda (1658), Frías (1698), Altamirano (1672), Burgués (1711), Machoni (1731), Rico (1748), entre muchos otros, traían consigo, además de nuevos jesuitas, muchos libros para sus bibliotecas, como a su vez para conventos y particulares. Y esos nuevos reclutas también traían libros, como señaló el P. Paucke (2010, p. 470), que cuenta haber llevado libros en su viaje de Europa a Buenos Aires, además de otros "adquiridos en Las Indias o había recibido de regalo por buenos amigos". Muchos de estos últimos y por su gentileza eran considerados "bienhechores" de la Compañía de Jesús. Estos ingresos de libros, no solo iban a la Universidad sino a todos los domicilios jesuíticos, incluyendo sus estancias. También se destinaban algunos para la venta, y para el caso, el general Tirso González en carta al provincial de 1699 manifestaba "no me parece malo el medio que se propone de que los procuradores cuando vienen, llevan los libros necesarios, que después se diesen a los estudiantes en aquel precio", obviamente sin buscar ganancia alguna (Page, 2013, p. 266).

Para la expulsión, se inventariaron todos los bienes de los jesuitas, y entre ellos, los libros. Bibliotecas que luego quedaron desintegradas formando otras, o parcialmente en manos de los oficiales a cargo de los inventarios, como parte de pago de sus honora-

\footnotetext{
${ }^{1}$ Autores indígenas como el cacique Nicolás Yapuguay, cuyos libros: "Explicación del catecismo en lengua guaraní" y "Sermones y ejemplos en lengua guaraní...”, fueron impresos en Santa María en 1724 y San Javier en 1727, respectivamente. Otros guaraníes menos populares fueron Vázquez, que posiblemente publicó el libro fechado en Loreto en 1709, Melchor que escribió una obra histórica y otro que compuso una historia del pueblo de San Francisco Javier (Furlong, 1993, p. 11). Pero también en la biblioteca del Colegio de Asunción, además de contabilizarse 4.519 volúmenes, se hallaron más de 200 manuscritos en guaraní (Gorzalczany y Olmos Gaona, 2006).
}

168 Silvana M. Lovay. Las bibliotecas de las estancias jesuíticas... 166-200. 
rios, o bien fueron vendidos junto a otros bienes muebles ${ }^{2}$. El objetivo u obsesión de estas listas era encontrar entre sus papeles, documentos o libros que los comprometieran y justificaran la misma expulsión, lo que llamaban libros de "doctrina relajada" u "obras laxas", pues se creía a los jesuitas como difusores de una literatura prohibida.

La Real Cédula del 23 de abril de 1767, publicada en las instrucciones del conde de Aranda sobre la expulsión, se refiere a cómo los jueces comisionados debían inventariar los libros, ejecutándose con "uniformidad en todas ellas, y con el debido método, distinción, y claridad". Eran 24 artículos donde se menciona primeramente la división de impresos y manuscritos; la confección del índice, que debía comenzar con el apellido del autor ubicado alfabéticamente, seguido del nombre entre paréntesis y luego todo el título de la portada, el lugar y año de impresión. Incluso eran conscientes que una encuadernación podría contener más de una obra, para lo que debían hojearla meticulosamente. Se prefería que para el inventario de libros se llamaran en lo posible a libreros y "gente versada" que al mismo tiempo hicieran su tasación. Es más, en el artículo XVIII menciona que los libros de las "granjas, ó residencias anexas á los Colegios" debían añadirse al índice de libros de la respectiva casa (Colección, 1767, pp. 47-49). Además de esta Real Cédula, se envió una Carta Circular donde se explicita autores prohibidos como Calatayud y Busenbaun, obras que estaban aquí y en todas las bibliotecas jesuíticas. Pues de tal manera que nada de estas normas se cumplieron o se hicieron mal los inventarios, al menos en Córdoba. Aunque no sorprende que en otros lugares fuera igual, del que se toma un caso al azar, como fue en el colegio de Orihuela donde el gobernador se lo comunica con ligereza al conde de Aranda (Mateo Ripoll, 2002, p. 58).

No se pretende profundizar en el tema, pues ya se ha hecho en reiteradas oportunidades (Martínez Villada, 1919; Cabrera, 1930; Torre Revello, 1940; Furlong, 1944), aunque poco y nada se ha escrito sobre las bibliotecas de los establecimientos rurales cordobeses, debiendo considerarse los más importantes, al ser los que abastecían las instituciones más relevantes de la provincia jesuítica del Paraguay. Decir solo que se ha conservado un índice de los libros del Colegio Máximo, fechado en 1757 distribuido en tres volúmenes y que contiene un reglamento de nueve puntos (Llamosas, 2000b y Fraschini, 2003). Pero que no es ni más ni menos que el mencionado en Regulae Praefecti Bibliothecae al que se le suprimieron los puntos 9, 10 y 11.

Para el caso de Santa Catalina nos valemos de dos inventarios de la expulsión, ya que no se cuenta con ningún otro de la época jesuítica ${ }^{3}$. Esa información que brindan los relevadores a la hora de inventariar es en muchos casos insuficiente para determinar

\footnotetext{
${ }^{2}$ AHUNC, Legajo 11 - A - Julio 1772. $1^{\circ}$ Cuenta, f. 5373. Relación de los libros que se han vendido por dirección de Don Fernando Fabro de los que se hallaron en el secuestro hecho a los Jesuitas expulsos en la Ciudad de Córdoba del Tucumán desde 12 de julio de 1767 hasta fines de diciembre de 1768.

${ }^{3}$ El primer inventario que se confeccionó de los bienes de los jesuitas de Córdoba (Argentina), se realizó desde julio de 1767 y por varios meses. La tasación de ese inventario se hizo en 1769. Pero en esos dos años, varios bienes muebles desparecieron de manos de sus administradores, por tanto no coinciden los inventarios de 1767 y 1769. El primero se perdió hace mucho tiempo, pero en 1771 se hizo un traslado, por lo que quedó registrado y transcribimos hace varios años. Ambos (1767-1771 y 1769) corrieron desgracias distintas: el primero apareció en el Archivo Histórico de la Provincia de Córdoba y el segundo en el Archivo General de la Nación, documentación esta última que se trasladó en 2001 al Archivo Histórico de la Universidad Nacional de Córdoba donde se digitalizó. Pero he aquí que el primer inventario compuesto de 482 fojas, es decir el que se encontraba en el Archivo de la Provincia, con el traslado que se hizo en 1771 del primer inventario de 1767, fue robado recientemente (después de 2011). La información de ese expediente constituye un caudal importante de información documental manuscrita que se conoce sobre el Colegio Máximo de la Provincia Jesuítica del Paraguay y sus seis estancias.
}

169 Silvana M. Lovay. Las bibliotecas de las estancias jesuíticas... 166-200. 
el libro al que se refieren. Obviamente que los años de ediciones no se mencionan y la mayoría de ellos tuvo varias. Todo esto resulta una tarea complicada al momento de realizar una clasificación temática.

$\mathrm{Ni}$ siquiera se han conservado los inventarios de los libros de todas las estancias. Solo de Caroya, donde fray Gregorio de Azcona OF, tazó 31 títulos y en Jesús María 61. En tanto que Candelaria y San Ignacio posiblemente los tenían, según Llamosas (2000b, p. 52). Mientras que no se registran libros en el inventario de la estancia de Alta Gracia, solo hay una escueta referencia en su inventario, sobre "una mesa y estantes para colocar libros". Con lo que creemos que los encargados del inventario de estas tres últimas estancias ${ }^{4}$ no consignaron los libros, o que el comisario Dr. Aldao respetó en mayor medida las órdenes del conde de Aranda.

Según Calixto Núñez (1980, p. 137) en la estancia de Santa Catalina, "había biblioteca, alojada en la segunda habitación de alto encima de lo que fue el Refectorio, siguiendo a la que fuera del Padre Lozano, con tribuna en la parte derecha del crucero de la iglesia, frente a la Dolorosa", información que no consta documentada. En 1729, un memorial del provincial Lorenzo Rillo dirigido al administrador de la misma estancia, observa: "No se permita que alguno, aunque sea cura preste ni llene fuera de la estancia libro alguno de ella; y se hará diligencia para cobrar las que se huvieren prestado" (Barrabino, 2014, p. 251). Este punto estaba claramente referenciado para todas las bibliotecas jesuíticas.

No mucho más se sabe de esta biblioteca que, recordemos era la de la estancia de la provincia y el noviciado, hasta que llegó la expulsión. Efectivamente, el capitán general Francisco de Paula Bucarelli y Ursúa, gobernador y capitán general de las provincias del Río de la Plata, Paraguay y Tucumán, envió a Santa Catalina, a través del superintendente de las Temporalidas sargento mayor Fernando Fabro, para hacer cumplir el Real Decreto de Extrañamiento, al Dr. Antonio Aldao, abogado de la Real Audiencia de Charcas y vecino de la ciudad. Lo acompañaron el escribano Ignacio Antonio Álvarez y el clérigo José Ordóñez, quien se ocuparía del inventario de la iglesia ${ }^{5}$. Llegaron a la estancia con la tropa y milicianos de auxilio, en la madrugada del 12 de julio de 1767 . Golpeó la puerta el teniente Francisco Rodríguez e inmediatamente agrupó a los jesuitas que se encontraban en el establecimiento, los PP. Andrés Bulnes, José Guevara y José Antonio de la Torre, los HH. Diego Millán, José Kobe y el novicio Pedro Céspedes ${ }^{6}$. Se separó al novicio, y al resto se los llevó a una habitación donde se les leyó el Decreto. Comenzaron el inventario general el día 16 con la iglesia, al día siguiente la casa y así hasta llegar a la biblioteca y comenzar con el inventario entre los días 20 y 21 de julio.

El primer índice se elaboró de acuerdo a cómo iban guardando ciertos bienes en cajones. Es decir que no hubo una nómina de autores por orden alfabético, ni un orden

\footnotetext{
${ }^{4}$ Los enviados por el sargento Fernando Fabro a Candelaria, San Ignacio y Alta Gracia fueron el vecino de Córdoba Diego de las Casas, como juez de comisión, el vecino de Buenos Aires Rafael Calvo y Mariño como escribano habilitado al efecto y el clérigo Martín Gurmendi encargado de inventariar las iglesias.

${ }^{5}$ Los dos primeros confeccionaron los inventarios de Santa Catalina, Jesús María y Caroya de los que señalaron los libros. Mientras que al Dr. Aldao, por haber trabajado 110 días le pagaron \$ 440 y al escribano $\$ 413$.

${ }^{6}$ Estos son los que menciona el inventario. Pero también se encontraban los HH. Antonio Harschl y José Ramos (Storni, 1980, pp. 137 y 233). En cuanto al joven Céspedes, según Storni, ese día se encontraba en el Noviciado (Storni, 1980, p. 33) y agrega Peramás que estaba enfermo en el noviciado, haciendo sus votos en barco de viaje a España (Page, 2011, pp. 398, 449 y 463).
}

170 Silvana M. Lovay. Las bibliotecas de las estancias jesuíticas... 166-200. 
por materia, ni siquiera se especificó si alguno de esos libros se encontraba en alguna habitación de los padres que habitaban la estancia. Se hizo con total laxitud e inexperiencia con un proceder superficial. De tal manera, que los libros se anotaron y acomodaron en 6 cajones y un cajoncito, para ser trasladados a Córdoba ${ }^{7}$. En el cajón $\mathrm{N}^{\mathrm{o}} 18$ se colocaron 12 títulos, 3 cartillas, 2 palmatorias, una despabiladera ${ }^{8}$ y una escobilla y un coleto de cordoban ${ }^{9}$. En el cajón 19 se colocaron 55 títulos, en el 20 suman 41 títulos, en el 21 contamos 31 títulos más un manuscrito; en el 22 la suma de 43 títulos. Luego se describe un cajoncito con el número 23 con 7 títulos y finalmente el cajón 24 con 19 obras. Es decir que en la biblioteca de la estancia se inventariaron en 1767 un total de 208 títulos en 424 volúmenes. Algunos de ellos están repetidos y de otros faltan volúmenes a la edición. Otros también se encuentran registrados en el Index, aunque hay obras que solo se hallan en la estancia.

El segundo inventario, iniciado el 10 de julio de 1769 se hizo porque al anterior no se lo había tasado, es decir no se le había puesto valor a los bienes. Esta vez el superintendente de las Temporalidades envió a Santa Catalina, como a las de Caroya y Jesús María, al escribano Antonio de las Heras Canseco y otros vecinos "especialistas" en platería, mensuras, edificios y libros. Para este último se encomendó otra vez al franciscano Gregorio Azcona ${ }^{10}$.

Como sugerimos antes, las descripciones son muy exiguas, sino falta el autor, carece del título, o bien este último se lo generaliza de tal forma que es imposible ubicar la obra.

No obstante podemos identificar dos grandes áreas temáticas: religiosa e historia, en todas sus variantes, y que veremos al final. Pues quizás no nos deberían que sorprender los libros de agricultura, aunque contaban con uno solo que no se ha identificado, aunque podría ser una de las obras del jesuita latinista Carlo d'Aquino que incursionó en varios géneros, o el científico español Gabriel Alfonso de Herrera, cuya obra fue encargada por el cardenal Cisneros.

En orden temático siguen los libros de medicina, como el del Papa Juan XXI del que hubo incontables ediciones, que fueron aumentando información y muy probablemente el de la estancia era la de Vilanova de 1655 reeditada en 1747 . Pero no era el único, ya que se contaba con la obra del francés Guy de Chauliac sobre cirugía, que si bien se escribió en latín en 1363, se convirtió en uno de los manuales más consultados de los siguientes tres siglos, por lo que se hallan múltiples ediciones. Aunque había varios más, como el de Guido de Cauliaco al que se consideraba príncipe de la cirugía. Otro especialista en cirugía fue el naturalista del siglo XVI Juan Fragoso, cuya obra también tuvo incontable ediciones, al igual que el cirujano Jerónimo de Ayala, de una amplia formación cultural. A su vez se encontraba en la biblioteca alguna de las obras de Sebastiano Bado que había difundido las propiedades de lo que se llamaba "corteza peruana" o también "corteza jesuítica" y "corteza de quina", aunque es una de las diver-

\footnotetext{
${ }^{7}$ Todos los bienes se ubicaron en cajones, desde los ornamentos de la iglesia, instrumentos de música, géneros, herramientas, etc.

${ }^{8}$ La palmatoria es un platillo y provisto de asa en el borde, ideado para sostener una vela en un soporte cilíndrico hueco. Las despabiladeras son unas tijeras que se usan para extinguir velas o candiles encendidos, quitando la pavesa, que es la parte ya quemada de la mecha.

${ }^{9}$ Un coleto era una casaca o chaleco de cuero, por lo común de cordobán o de ante (piel de cordero), abierta por delante y con una especie de faldón que cubría desde el cuello hasta la cintura.

${ }^{10}$ AHUNC, Caja 3 N 5 Leg 11, ff. 1154v-1162.
}

171 Silvana M. Lovay. Las bibliotecas de las estancias jesuíticas... 166-200. 
sas variantes del género Cinchona, con múltiples propiedades curativas. Dos obras que compendiaban todos los aspectos de la medicina, fueron las de Juan de la Torre y Balcárcel, y la del coadjutor jesuita Juan de Steinhofer que trabajó como médico itinerante en las misiones del noroeste de México, cuya obra allí impresa se editó tres veces en el siglo XVIII.

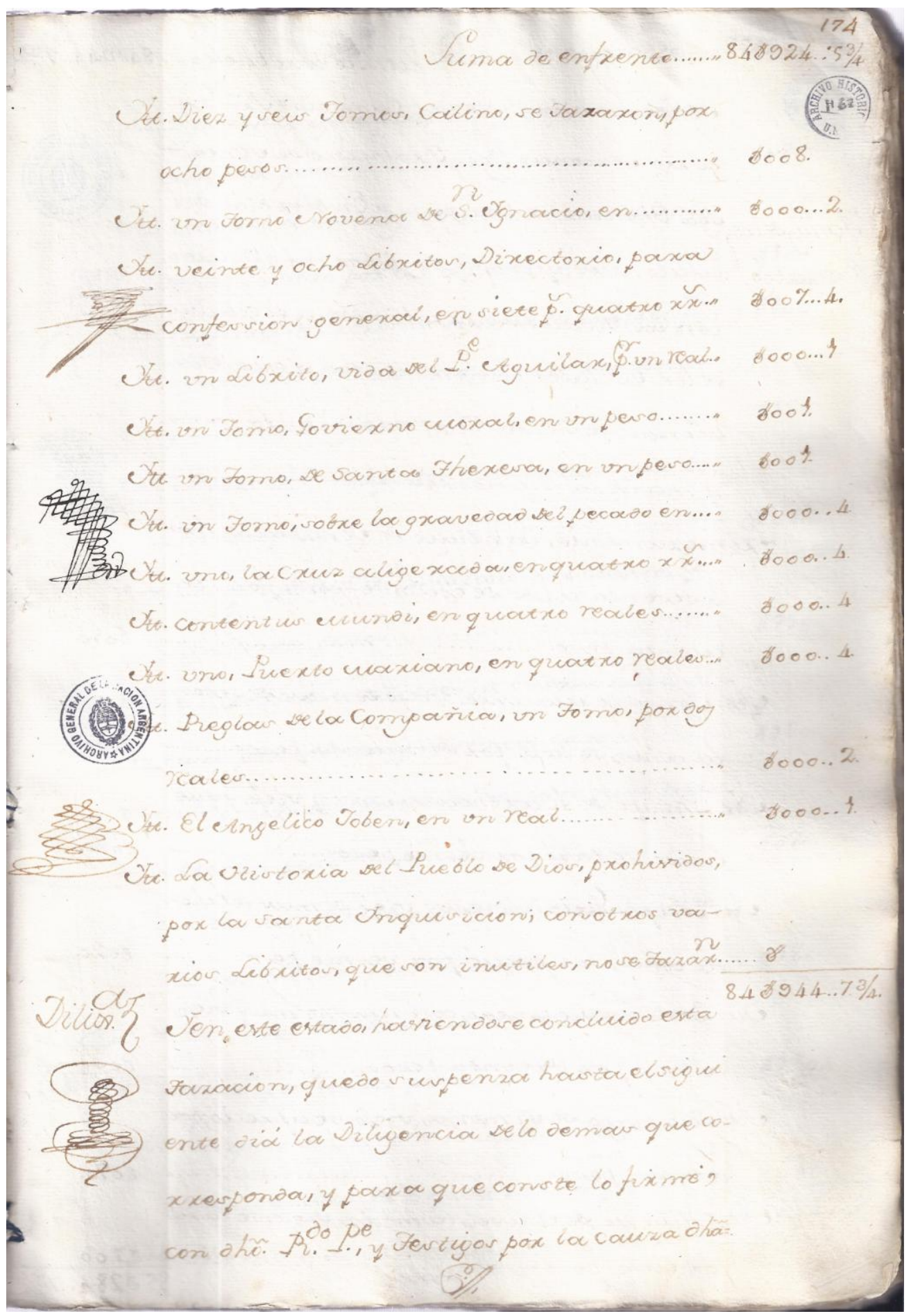

Uno de los folios del inventario de los libros de la estancia de Santa Catalina del AHUNC (Caja 3 N $^{\circ} 5$ Leg 11).

172 Silvana M. Lovay. Las bibliotecas de las estancias jesuíticas... 166-200. 
Están presentes obras clásicas jurídicas como la del madrileño Juan de Solórzano y Pereyra, y a su vez la del no menos conocido dominico Torquemada, uno de los mentores de la inquisición en España.

Diccionarios no faltaban y eran necesarios en la estancia donde realizaban gran parte de sus trabajos los historiadores de la provincia. Desde el de Covarrubias, obra que precedió al de Autoridades de la RAE y del que la estancia contaba con sus seis tomos Uno en francés-castellano del oficial del Ejército de Flandes, maestro en lengua española Francisco Sobrino, que vino a coronar una serie de seis diccionarios bilingües.

Otra variedad de obras se dan por ejemplo en un libro clásico de arquitectura como el de fraile de la Orden de los Agustinos Recoleto fray Lorenzo, conocido arquitecto de la corte española, interesado en la formación de profesionales. En temas jurídicos destaca Murillo Velarde del que la biblioteca poseía dos obras, un catecismo y otro sobre derecho canónico que incluía leyes de España e Indias, publicado cuando residía en Filipinas donde era profesor de derecho civil y canónico en Manila. No faltaron obras literarias como la Araucana, el poema épico del español Alonso de Ercilla, que relata la guerra de Arauco de la que participó. Su libro fue publicado en tres volúmenes que aparecieron bastante distanciados uno del otro (1569/1578/1589), pero que tuvieron una enorme repercusión; autor halagado desde Cervantes a Voltaire. Finalmente entre las obras de gran lingüista jesuita Ruiz de Montoya, figura su Vocabulario, del que nos quedará la duda si fue la edición española o la mejorada de la imprenta de las misiones.

Como expresamos antes, los libros religiosos e históricos son los que prevalecen. El inventario comienza con los Ejercicios del jesuita vallisoletano Alonso Rodríguez, basado en las pláticas semanales que realizó entre 1589 y 1595. Los últimos toques de la obra se efectuaron en la publicación de 1615, antes de su muerte. Tuvo más de 300 ediciones en varios idiomas. Y así como esta obra, sobresalen los autores jesuitas. Clásicos como los trabajos del exegeta, filósofo y polígrafo Nieremberg, con obras de espiritualidad tan profundamente apegadas a muchas generaciones cristianas. Se encontraban cuatro obras, de las que se destaca la Diferencia de lo temporal... del que también quedan dudas si una de las dos que había, no era de la imprenta jesuítica. Temas devocionarios como la novena de San Ignacio, o el Manual del vallisoletano Villacastín (1612), sobre los cuatro novísimos de Francisco de Salazar publicado por primera vez en 1628. La Mística ciudad de Dios de la Madre Venerable sor María de Jesús de Agreda, única autora mujer de la biblioteca, obra póstumamente en 1670 que fue prohibida por la Inquisición entre 1681-1686, y luego que se autorizara se han impreso 173 ediciones en varios idiomas, convirtiéndose en un libro muy popular en su tiempo.

Podríamos seguir enumerando autores como el jesuita francés Cerutti, cuya Apología fue dirigida por el profesor Menoux, compuesta en Nancy en 1762 y que salió de imprenta sin nombre de autor. Los discursos sobre la casa de Loreto que regenteaban los jesuitas del P. Torselino. El moralista alemán Busenbaum con su pequeño libro que ha sido alabado y censurado como pocos desde 1757. Por su parte el P. Cousin en su Regnum Dei, contenía ciertas expresiones atrevidas que irritaron al cardenal Giulio Mazarino y le llevaron de nuevo al destierro. Las verdades eternas del conocido P. Rossignoli, publicada en Milán en 1688 de que la estancia seguramente tuvo la versión castellana de 1725. Mientras que autores no pertenecientes a la Compañía de Jesús se destaca José de Barcia y Zambrana obispo de Cádiz, con su Despertador Christiano que tuvo múltiples ediciones desde 1678.

173 Silvana M. Lovay. Las bibliotecas de las estancias jesuíticas... 166-200. 
Imposible resaltar autores de la talla que se encontraban en la biblioteca. Ni los que asumían temas religiosos, hasta los históricos. De estos últimos, también son mayoría los jesuitas, incluso de la propia provincia del Paraguay, como Fernández sobre la historia de chiquitos, Lozano y Montoya, mientras que de Machoni curiosamente no se encontraba sus Siete Ángeles, pero sí otras obras. Ya Jarque había publicado la vida de Ruiz de Montoya y el género ya tenía amplia difusión en obras desde el Flos Santorum, pasando por Patrignani hasta el martirologio de Baronio. Vidas de personajes importantes desde la de San Ignacio de Fluvio, como la de Alfonso Rodríguez del P. Colín y Luis de la Puente del P. Cachupin, el de Cabral de los 40 mártires del Brasil, obra por cierto muy rara. Pero también ya habían aparecido las historias de provincias como las de Chile de Ovalle y la del Paraguay de Charlevoix, del que también la biblioteca contaba con otras de sus obras históricas. Otra enorme serie de producciones editoriales fueron las cartas de San Francisco Javier y sobre todo las de Diego Davin que tuvieron tanta repercusión en su tiempo.

La escasa información que nos brinda el inventario de Temporalidades nos limita el método de catalogación del fondo. De tal manera que ubicamos en la columna izquierda su ubicación en los siete cajones mencionados, luego la transcripción de su designación en el inventario y a la derecha el autor y título, que en muchos casos estimamos posible, dejando en suposición el lugar y año de publicación que no se mencionan. El asterisco indica que también figuran en la tasación realizada entre el 8 y 10 de enero de 1769 por el mismo franciscano fray Gregorio Azcona y el escribano Antonio las Heras Canseco. De tal manera que de los 208 títulos contabilizados en 1767, debemos agregar que 45 no figuraban en 1769, sin embargo en esa tasación se agregan 34 obras que no fueron mencionados en el primer inventario de 1767 . De tal manera que la biblioteca contaría con unas 242 obras y 464 volúmenes.

\begin{tabular}{|c|c|c|}
\hline : & Designación en Inventario & Autor y obra \\
\hline \multirow{3}{*}{ 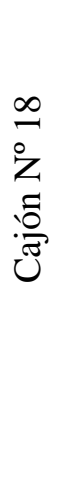 } & $\begin{array}{l}* 3 \text { tomos Ejercicios de Ro- } \\
\text { driguez }\end{array}$ & $\begin{array}{l}\text { Rodríguez SJ, Alonso (1538-1616). Ejercicio de perfección } \\
\text { y virtudes cristianas (Sevilla, 1609/1613/1727). }\end{array}$ \\
\hline & $\begin{array}{l}\text { *Otro dialogo en español y } \\
\text { francés }\end{array}$ & $\begin{array}{l}\text { Oudín, César (c. 1560-1625). Dialogues en fraçois \& es- } \\
\text { pagnol... avec des Annotations... de quelques difficultez Es- } \\
\text { pagnoles...: avec un Nomenclator de quelques particularitez } \\
\text { qui se presentent à tout propos (Bruselas, 1604). }\end{array}$ \\
\hline & $\begin{array}{l}\text { *Apologia del Instituto de } \\
\text { la Compañía }\end{array}$ & $\begin{array}{l}\text { Cérutti SJ, Jean-Antoine-Joachim (1738-1792). Apologie } \\
\text { générale de l'Institut et de la doctrine des Jésuites. (Aviñón, } \\
\text { 1765) } 2 \text { tomos. }\end{array}$ \\
\hline
\end{tabular}

174 Silvana M. Lovay. Las bibliotecas de las estancias jesuíticas... 166-200. 


\begin{tabular}{|c|c|}
\hline $\begin{array}{l}\text { *Otro diferencia entre lo } \\
\text { temporal y eterno }\end{array}$ & $\begin{array}{l}\text { Nieremberg SJ, Eusebio (1595-1658). De la diferencia } \\
\text { entre lo temporal y lo eterno. Crisol de desengaños (Madrid, } \\
1640)^{11} .\end{array}$ \\
\hline *Otro Platicas espirituales & Información insuficiente ${ }^{12}$. \\
\hline *Otro Tesoro de pobres & $\begin{array}{l}\text { Juan XXI (1215-1277). Libro de medicina llamado Tesoro } \\
\text { de pobres: en que se hallaran remedios muy aprobados para } \\
\text { la sanidad de diversas enfermedades: con un Regimiento de } \\
\text { sanidad / compuesto por el maestro Julian, que le recopiló } \\
\text { de diversos autores; ahora nuevamente corregido y enmen- } \\
\text { dado por Arnau de Vilanova (1238-1311) (Sevilla, 1655). }\end{array}$ \\
\hline *Otro Novena de S. Ignacio & Información insuficiente ${ }^{13}$. \\
\hline $\begin{array}{l}\text { *Otro Villascastin manual } \\
\text { de Ejercicios }\end{array}$ & $\begin{array}{l}\text { Villacastín SJ, Tomás de (1570-1649). Manual de conside- } \\
\text { raciones y exercicios espirituales para saber tener oración } \\
\text { mental (Valladolid, 1612). }\end{array}$ \\
\hline Un librito de Vida cristiana & Información insuficiente ${ }^{14}$. \\
\hline $\begin{array}{l}\text { Otro consideraciones sobre } \\
\text { los cuatro novísimos }\end{array}$ & $\begin{array}{l}\text { Salazar SJ, Francisco de (1559-1599). Afectos y Considera- } \\
\text { ciones devotas sobre los quatro Novissimos. Por primera vez } \\
\text { incluido en la Suma teológica de Fr. Jerónimo Pérez (Madrid, } \\
1628)^{15} \text {. }\end{array}$ \\
\hline $\begin{array}{l}\text { *Otro, de los Ejercicios de } \\
\text { S. Ignacio }\end{array}$ & $\begin{array}{l}\text { Loyola SJ, San Ignacio de (1491-1556). Exercitia spiritva- } \\
\text { lia (Roma, 1548) }\end{array}$ \\
\hline $\begin{array}{l}\text { Otro, Para reducir a reales } \\
\text { de vellón todo género de } \\
\text { moneda }\end{array}$ & $\begin{array}{l}\text { Asensio y Mejorada, Francisco (1725-1794). Nuevo uso y } \\
\text { provechoso para reducir á reales de vellon, conforme á la } \\
\text { Real Pragmatica de } 17 \text { de Mayo de } 1737 \text { todo género de } \\
\text { moneda corriente, como doblones en oro, pesos gruessos, } \\
\text { pesetas ... con el nuevo cuño de Columnas, y mundos (Ma- } \\
\text { drid, 1758). }\end{array}$ \\
\hline 3 cartillas & Información insuficiente. \\
\hline
\end{tabular}

\footnotetext{
${ }^{11}$ De esta obra se imprimieron múltiples ediciones, incluso en la imprenta de las reducciones en su versión guaraní, traducida por el P. José Serrano e impresa en 1705.

${ }^{12}$ Puede ser el libro de Pláticas Espirituales del P. Gerónimo Nadal (1561), Pláticas y collaciones espirituales de Luis de Miranda (1618) o Pláticas domésticas espirituales de Juan Paulo Oliva (1680).

${ }^{13}$ Pueden ser Lorenzo Martini, Novena da farsi ad honere di S. Ignatio Conf. Fondatore della Compa. Di Gesu... (Roma, 1663), o Novena á San Ignacio de Loyola ... traducida en español, de su original italiano por D. Antonio Fernandez de Lossa (Madrid, 1752).

${ }^{14}$ Podría ser el popular del navarro Jerónimo Dutari SJ (1671-1717). Vida cristiana ó Practica facil de entablarla con medios y verdades fundamentales contra ignorancia o descuidos comunes (Salamanca, 1718). Llegó a tener 18 ediciones de un poco más de $150 \mathrm{pp}$.

${ }^{15}$ Luego tuvo más de 100 ediciones.

${ }^{16}$ Posteriormente hubo múltiples ediciones.
}

175 Silvana M. Lovay. Las bibliotecas de las estancias jesuíticas... 166-200. 


\begin{tabular}{|c|c|c|}
\hline & $\begin{array}{l}2 \text { palmatorias y una espabi- } \\
\text { laderas / Una escobilla y un } \\
\text { coleto de cordobán }\end{array}$ & \\
\hline \multirow{9}{*}{ 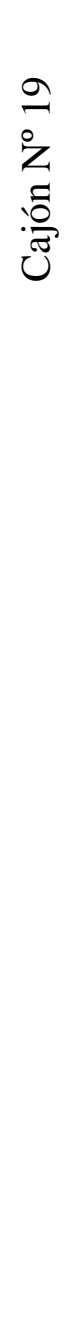 } & *Un tomo de Diana & Información insuficiente $^{17}$. \\
\hline & Resoluciones morales & Información insuficiente $^{18}$. \\
\hline & *Uno guido de cirujía & $\begin{array}{l}\text { Cauliaco, Guido de (1290?-1368). La magna y canonica } \\
\text { cirvgia de Gvido de Cavliaco, prinicipe della. Con la glosa } \\
\text { del Doctor Falcon, y lo que a su modo dispuso el Doctor } \\
\text { Calvo... (Madrid, 1658). }\end{array}$ \\
\hline & $\begin{array}{l}\text { *Dos tomos de la Política de } \\
\text { Solórzano }\end{array}$ & $\begin{array}{l}\text { Solórzano y Pereyra, Juan de (1575-1655). Política india- } \\
\text { na, sacado en lengua castellana de los dos tomos del dere- } \\
\text { cho; govierno municipal de las Indias Occidentales (Madrid, } \\
\text { 1647). }\end{array}$ \\
\hline & $\begin{array}{l}\text { *Un tomo de la Mística } \\
\text { Ciudad de Dios }\end{array}$ & $\begin{array}{l}\text { Agreda, María de Jesús de (1602-1665). Mystica ciudad de } \\
\text { Dios, milagro de su omnipotencia, y abismo de la gracia: } \\
\text { Historia divina y vida de la Virgen Madre de Dios... (Ma- } \\
\text { drid, 1670). }\end{array}$ \\
\hline & $\begin{array}{l}\text { *Un tomo, Coronica de la } \\
\text { Compañía }\end{array}$ & $\begin{array}{l}\text { Alcázar SJ, Bartolomé (1648-1721). Chrono-historia de la } \\
\text { Compañia de Jesvs, en la Provincia de Toledo y elogios de } \\
\text { svs varones illustres, bienhechores, fautores e hijos espiritua- } \\
\text { les... (Madrid, 1710), } 2 \text { tomos }{ }^{19} \text {. }\end{array}$ \\
\hline & Otro Práctica del Ayuno & Información insuficiente. \\
\hline & $\begin{array}{l}\text { *Otro Discursos Ystoriales } \\
\text { de Loreto }\end{array}$ & $\begin{array}{l}\text { Torsellino SJ, Orazio (1544-1590). Discursos historiales } \\
\text { panegyricos de las glorias de la serenissima Reyna de los } \\
\text { angeles en sv sagrada casa de Loreto (Madrid, 1671). }\end{array}$ \\
\hline & Otro Los Cánticos de Sa- & Información insuficiente ${ }^{20}$. \\
\hline
\end{tabular}

\footnotetext{
${ }^{17}$ Se refiere al teatino laxista Antonio Diana (1585-1663) que escribió entre muchas obras: 1- Resolutionum moralium pars prima et secunda, 2- Summa Dianae y 3- De promatu solii D. Petri disceptationes apologeticae.

${ }^{18}$ Faltan datos, pueden ser con ese título el libro de Pedro Aíngo Ezpeleta (1643), Acacio March de Velasco (1656), Antonio de Quintanadueñas (1660), entre muchos otros. Incluso Diana citado arriba.

${ }^{19} \mathrm{Si}$ bien la referencia del inventario es escasa y abreviada, la única obra que lleva por título la palabra "crónica" de la Compañía, es la del P. Alcázar, redactada a principios del siglo XVIII que tuvo como fuentes principales las obras impresas de los PP. Orlandini y Sacchini. Si bien el título especifica la provincia de Toledo, creada en 1562, el autor comienza con la fundación de la Orden en 1540, extendiéndose hasta 1580 e incluso extendiéndose a otras naciones cuando intervienen jesuitas ligados a aquella provincia. En el cajón 23, con una denominación parecida, quizás se refiera al otro tomo de Alcázar.

${ }^{20}$ Pueden ser 1-Pinto Ramírez SJ, Andrés (1595-1654). Canticum canticorum Salomonis dramático tenore (Lyon, 1642), 2-Salazar SJ, Fernando Quirino de (1576-1646). Canticum canticorum Salomonis allegorico sono et prophetica, mystica, hypermistica expositione productum. (Lyon, 1642) 2 tomos. 3Sotomayor OP, Luis de (1506-1590). Cantice Canticorum Salomonis interpretattio (Paris, 1599/1605) 2 tomos. 4-Ghislerius, Michael (1564-1646). Comentaria in Canticum Canticorum Salomonis iuxta lectiones vulgatam, hebraeam \& graecas interpretum (Antuerpiæ, 1615). 5-Albiniano de Raias SJ, Paulo (1583-1667). In Canticum litterales in Canticorum Salomonis (Génova, 1656). 6-Del Rio SJ, Martin

176 Silvana M. Lovay. Las bibliotecas de las estancias jesuíticas... 166-200.
} 
IHS. Antiguos Jesuitas en Iberoamérica ISSN: 2314-3908

Vol. 5 no 2

julio-diciembre 2017

\begin{tabular}{|c|c|}
\hline lomón & \\
\hline $\begin{array}{l}\text { *Otro que empieza en la } \\
\text { Sexta parte de Historia Pon- } \\
\text { tifical }\end{array}$ & $\begin{array}{l}\text { Baños de Velasco y Acevedo, Juan (1615-1682). Sexta } \\
\text { parte de la Historia Pontifical, General y Catholica ... (Ma- } \\
\text { drid, 1678). }\end{array}$ \\
\hline $\begin{array}{l}* 4 \text { tomos de la Vida de San } \\
\text { Francisco Xavier }\end{array}$ & Información insuficiente ${ }^{21}$. \\
\hline *Otro sobre la Agricultura & Información insuficiente ${ }^{22}$. \\
\hline *Olivan, Gobierno moral & $\begin{array}{l}\text { Olivan y Maldonado OCD, Antonio (¿?-1631). Govierno } \\
\text { Moral del Alma, reformador de vicios e instrvydor de virtu- } \\
\text { des por varios mixtos (Barcelona, 1623) } 2 \text { tomos. }\end{array}$ \\
\hline $\begin{array}{l}\text { *Un tomo los } 40 \text { mártires de } \\
\text { la Compañía }\end{array}$ & $\begin{array}{l}\text { Cabral SJ, Antonio (1693-1758). "Relacion del martyrio } \\
\text { de los quarenta martyres de la Compañia de Jesus. Vida del } \\
\text { Venerable Martyr P. Ignacio Acevedo, su superior. Que dio } \\
\text { a luz el P. Antonio Cabral en idioma italiano, y nuevamente } \\
\text { traducida por un religioso de la misma Compañía" (Madrid: } \\
\text { 1744). }\end{array}$ \\
\hline *Otro universal redención & $\begin{array}{l}\text { Hernández Blasco, Francisco (1515/1520-1587). Universal } \\
\text { redempcion, passion, muerte y resurrecion de nuestro Re- } \\
\text { demptor Iesu Christo, y angustias de su santissima Madre } \\
\text { segun los quatro Euangelistas, con muy deuotas contempla- } \\
\text { cione (Alcalá, 1584/1598/1602/1609/1623/1628/varias). }\end{array}$ \\
\hline $\begin{array}{l}\text { *Otro de misiones de chi- } \\
\text { quitos }\end{array}$ & $\begin{array}{l}\text { Fernández SJ, Joan Patricio (1667-1733). Historica rela- } \\
\text { tio, de apostolicis missionibus patrum Societatis Jesu, apud } \\
\text { chiquitos, Paracuariae populos... }(1723)^{23} .\end{array}$ \\
\hline Otro Prontuario moral & $\begin{array}{l}\text { Salas y Trillas, Pedro (1700-1781). Promptuari moral sa- } \\
\text { grat y cathecisme pastoral, de pláticas doctrinals y espiri- } \\
\text { tuals sobre tots los punts de la Doctrina Christiana, per } \\
\text { predicar en la Quaresma, Diumenges, y demés festivitats } \\
\text { ocurrents..., } 5 \text { t. (Barcelona, 1755-1757). }\end{array}$ \\
\hline *Un tomo Meviologio de & Traslado del menologio de varones illustres de la Compañía \\
\hline
\end{tabular}

Antoine (1551-1608). In Canticum Canticorum Salomonis (Ingolstadt, 1604). 7- Ormachea y Guerrero, Jerónimo (¿?). Commentaria in Cantica Canticorum Salomonis (Logorño, 1637), etc.

${ }^{21}$ Se refiere a que habría 4 ejemplares. Varios autores escribieron sobre esta biografía en latín y castellano. Torsellini (1594, 1596, 1600); Villacastín (1620); Sanvitores (1661); Bartoli (1666); García (1673, 1676, 1683)

${ }^{22}$ En el inventario de 1769 expresa "Secretos de Agricultura". También podrían ser Carlo d' Aquino SJ, (1654-1737). Nomenclator Agricultura (Roma, 1736), que se encontraba en el Colegio Máximo o Gabriel Alfonso de Herrera (1470-1539). Obra de Agricultura, copilada de diversos auctores por Gabriel Alonso de Herrera de mandado del muy ilustre y reverendíssimo señor el cardenal de España, arçobispo (Alcalá de Henares, 1513) (Con otros títulos similares, ediciones de 1520/ 1524/ 1528/ 1539/ 1546/ 1551/ 1563 , etc)

${ }^{23}$ La edición castellana Relación historial de las missiones de los indios que llaman Chiquitos que están a cargo de los Padres de la Compañía de Jesús de la Provincia del Paraguay (Madrid, 1726).

177 Silvana M. Lovay. Las bibliotecas de las estancias jesuíticas... 166-200. 


\begin{tabular}{|c|c|}
\hline $\begin{array}{l}\text { Varones Ilustres de la Com- } \\
\text { pañía }\end{array}$ & $\begin{array}{l}\text { de Jesus, cuyos elogios aprobados por Nuestros PP. Gene- } \\
\text { rales se leen los días, que corresponden en la Casa Professa } \\
\text { de Roma (Madrid, 1729). }\end{array}$ \\
\hline *Uno Basembaun & $\begin{array}{l}\text { Busenbaum SJ, Hermann (1600-1668). Medulla theologiae } \\
\text { moralis facili ac perspicua methodo resolvens casus } \\
\text { conscientiae ex variis probatisque auctoribus concinnata } \\
\text { (Münster, 1645). }\end{array}$ \\
\hline $\begin{array}{l}\text { *6 tomos ejercicios de } \\
\text { Rodríguez }\end{array}$ & Cit. Rodríguez SJ, Alonso (1538-1616). \\
\hline$* 2$ martirologio romano & $\begin{array}{l}\text { Baronio, César (1538-1607). Martyrologium Romanum ad } \\
\text { novam Kalendarii rationem et ecclesiasticae histórice veri- } \\
\text { tatem restitutum, Gregorii XIII Pont. Max. iussu editum } \\
\left(\text { Venecia, } 1584 / 1586(1630 / 1681 / 1698 / 1748 \text { etc. })^{24} .\right.\end{array}$ \\
\hline $\begin{array}{l}\text { *Otro Avisos de Santa Tere- } \\
\text { sa }\end{array}$ & $\begin{array}{l}\text { Andrade SJ, Alonso de (1590-1672). Avisos Espiritvales } \\
\text { de Santa Teresa de Jesvs comendados por el Padre Alonso } \\
\text { de Andrade (Madrid, 1647/ varios). }\end{array}$ \\
\hline $\begin{array}{l}\text { *Otro Fiestas del Colegio de } \\
\text { Salamanca }\end{array}$ & Información insuficiente ${ }^{25}$. \\
\hline *2 tomos de David & $\begin{array}{l}\text { Lozano, Cristóbal (1609-1667). David perseguido, y alivio } \\
\text { de lastimados. Historia sagrada parafraseada con exemplos, } \\
\text { y varias historias Humanas, y Divinas (Madrid, } 1652 \text { a } \\
\text { 1661) } 3 \text { tomos. }\end{array}$ \\
\hline $\begin{array}{l}2 \text { tomos hechos del V. Alon- } \\
\text { so Rodriguez }\end{array}$ & $\begin{array}{l}\text { Colín SJ, Francisco (1592-1660). Vida, Hechos y Doctrina } \\
\text { del Ven. H. Alonso Rodriguez (Madrid, 1652). }\end{array}$ \\
\hline $\begin{array}{l}2 \text { el Reino de Dios, su autor, } \\
\text { el P. Causino }\end{array}$ & Caussin SJ, Nicolas (1583-1651). Regnum Dei (París, 1650) \\
\hline *Uno de Anatomía & Información insuficiente ${ }^{26}$. \\
\hline
\end{tabular}

${ }^{24}$ Pero también podría haber sido el publicado en la imprenta jesuítica de las misiones guaraníticas: Mar-
tirologio Romano, Loreto, 1700 (Hoy, un ejemplar en Archivo General de la Nación (Argentina)
${ }^{25}$ Pueden ser, entre otros: 1-Fiestas que hizo el insigne Collegio de la Compañia de Iesus de Salamanca,
A la Beatificacion del glorioso Patriarcha S. Ignacio de Loyola ... (Colegio de la Compañia de Jesus de
Salamanca, 1610). 2-Antonia Ramirez viuda (¿?). Relacion de las fiestas que la universidad de Sala-
manca celebro desde 27. Hasta 31. De Octubre del ano de 1618. Al juramento del nuevo estatuto... De
que todos sus graduados defenderan la pura... Concepcion de la Virgen (Salamanca, 1618). 3- Luis de
Losada (1681-1748). La juventud triunfante representada en las fiestas con que celebro el Colegio Real
de la Compañia de Jesus de Salamanca la canonizacion de San Luis Gonzaga y San Stanislao Kostka
(Valencia, 1750)
${ }^{26}$ Pueden ser, entre muchos, 1- Martínez, Martín (1684-1734). Noches anatomicas o anatomia compen-
diosa (Madrid, 1716/1750). 2-Schott, Gaspar (1608-1666). Anatomia physico-hydrostatica fontium et
flumenum (Würtzburg, 1663). 3-Valverde de Amusco, Juan (1525-1587). Anatomia del cuerpo humano
composta por... (Roma, 1559/1560/1586/1589). 4-Bartholinus, Thomas (1616-1680). Anatome Ex om-
nium Veterum Recentiorumque Observationibus Imprimis Institutionibus b. m. parentis... (Lyon 1686).
5-Dionis, Petris (1643-1718). Anatomia corporis humani, juxta circulationem sanguinis \& recentiores
Observationes sanguinis... (Amsterdam, 1696). 6-Molina, Francisco (¿?).Tractado muy provechoso del 178 Silvana M. Lovay. Las bibliotecas de las estancias jesuíticas... 166-200. 


\begin{tabular}{|c|c|}
\hline $\begin{array}{l}\text { Otro de la vida del P. Luis } \\
\text { de la Puente }\end{array}$ & $\begin{array}{l}\text { Cachupin SJ, Francisco (1599-1678). Vida, y virtudes del } \\
\text { venerable padre Lvis de la Pvente de la Compañia de Iesus, } \\
\text { natural de la Civdad de Valladolid... (Salamanca, 1652). }\end{array}$ \\
\hline Otro del Superior instruido & $\begin{array}{l}\text { Machoni SJ, Antonio (1672-1753). El Nuevo Superior Re- } \\
\text { ligioso instruido en la práctica, y arte de governar por va- } \\
\text { rios dictamenes de la religiosa prudencia, sacados de la } \\
\text { sagrada escriptura, santos padres, y de las vidas, y hechos } \\
\text { de varones Ilustres en prudencia, santidad y experiencia. } \\
\text { (Puerto de Santa María, 1750/1753/1759). }\end{array}$ \\
\hline *Verdades eternas & $\begin{array}{l}\text { Rossignoli SJ, Carlo Gregorio (1631-1707). Verità eterne } \\
\text { esposte in Lezioni ordinate principalmente per il giorni degli } \\
\text { Esercizij spirituali (Milán, 1688/1725). }\end{array}$ \\
\hline *Otro Alphabeto moral & $\begin{array}{l}\text { Alloza SJ, Juan de (1597-1666). Flores summarum seu } \\
\text { alphabetum morale, omnium ferè casuum, qui confessariis } \\
\text { contingere possunt (Lieja, 1665). }\end{array}$ \\
\hline Un Breviario viejo & Información insuficiente ${ }^{27}$. \\
\hline $\begin{array}{l}* 10 \text { libritos Ejercicios de } \mathrm{S} \text {. } \\
\text { Ignacio }\end{array}$ & $\begin{array}{l}\text { Loyola SJ, Ignacio (1491-1556). Exercitia spiritvalia (Ro- } \\
\text { ma, 1548) }{ }^{28} \text {. }\end{array}$ \\
\hline $\begin{array}{l}* 20 \text { dichos Directorio para } \\
\text { confesión general }\end{array}$ & $\begin{array}{l}\text { La Puente SJ, Luis de (1554-1624). Directorio espiri- } \\
\text { tual de los santos sacramentos de la confesion y comunion, y } \\
\text { del santo sacrificio de la Misa, con exercicio de la oracion y } \\
\text { meditación (Sevilla, 1625). }\end{array}$ \\
\hline $\begin{array}{l}5 \text { tomos de Causino, La } \\
\text { corte Santa }\end{array}$ & $\begin{array}{l}\text { Caussin SJ, Nicolas (1583-1651). Il relato della Corte San- } \\
\text { ta, o'Istitutione christiana de'grandi (Bolonia, 1652). } 5 \text { to- } \\
\text { mos. }\end{array}$ \\
\hline Uno de la Historia oriental & $\begin{array}{l}\text { Mendes Pinto, Fernão (¿1510-1514?-1583). Historia } \\
\text { Oriental de las peregrinaciones de Fernan Mendez Pinto... } \\
\text { (Valencia, 1645). }\end{array}$ \\
\hline *Uno del P. Puente & $\begin{array}{l}\text { La Puente SJ, Luis de (1554-1624). Meditaciones de los } \\
\text { mysterios de nuestra sancta fe con la practica de la oracion } \\
\text { mental sobre ellos (Valladolid, 1605). }\end{array}$ \\
\hline 2 su autor Malleo & Información insuficiente ${ }^{29}$. \\
\hline
\end{tabular}

anatomia, y phlebotomia de venas y arterias y del anatomia de los nervios, con un tractado de ventosas y otro de sanguijuelas con un ... (Burgos, 1547).

${ }^{27} \mathrm{Si}$ bien aparecieron a fines del siglo XI, luego del Concilio de Trento se fijaron los textos y se le dio un formato completo. Infinidad de ediciones

${ }^{28}$ A partir de esta primera edición se sucedieron numerosas otras, publicadas en distintas ciudades y lenguas.

${ }^{29}$ Tomás de Kempis (Malleolus) (1380-1471). Imitación de Cristo, (manuscrito 1418-1441, primera ed 1494) La edición más completa hasta ahora de la "Opera Omnia" de Kempis es la del jesuita Henri de Sommalius (1533-1619), publicada por Nut de Antwerp, 1607; aun éste no contiene el "Chronicon Montis Sanctae Agnetis", que fue editado por H. Rosweyd S.J., y publicado en un volumen con el "Chronicon Windesemense".

179 Silvana M. Lovay. Las bibliotecas de las estancias jesuíticas... 166-200. 


\begin{tabular}{|c|c|}
\hline $\begin{array}{l}\text { *Un librito sobre La grave- } \\
\text { dad del pecado }\end{array}$ & Información insuficiente ${ }^{30}$. \\
\hline $\begin{array}{l}* \text { Uno de las calidades de la } \\
\text { corteza peruana }\end{array}$ & $\begin{array}{l}\text { Bado, Sebastiano (activo 1643-1676). Corteza Peruviae } \\
\text { redivivus proffigator febrium assertus ab impugnationibus } \\
\text { médicos Melippi Protimi belgae en San Bado Médico Ge- } \\
\text { nuense, magnae De Sereniss. Matri Coeli Reginae Mariae } \\
\text { (Génova, 1656) o Anastasis Corticis Peruviae, seu Chinae } \\
\text { Chinae defensio Sebastiani Badi Genuensis, Patrii Utrius- } \\
\text { que Nosocomii médicos olim, et publicae Sanitatis Consul- } \\
\text { toris, ventilationes contraindicaciones Ioannis Iacobi Chi- } \\
\text { fleti, gemitusque Vopisci Lucky Pemplii illustrium medico- } \\
\text { rum, obra en tres libros distinctum, et in eis documentos } \\
\text { medicinae et philosophiae (Génova, 1661). }\end{array}$ \\
\hline *Otro frágora de Cirugía & $\begin{array}{l}\text { Fragoso, Juan (c.1530-1597). Chirugia universal (Madrid, } \\
\text { 1581/1586/1592/1596/1601). }\end{array}$ \\
\hline $\begin{array}{l}\text { *Uno Compendio de la me- } \\
\text { dicina }\end{array}$ & $\begin{array}{l}\text { Torre y Balcárcel, Juan de la (¿?- ¿?). Espejo de la philo- } \\
\text { sophia y compendio de toda la medicina theorica y practica. } \\
\text { (Pamplona, 1668/1705/1715). }\end{array}$ \\
\hline *Otro Florilegio medicinal & $\begin{array}{l}\text { Steinhofer SJ, Juan de (1664-1716). Florilegio medicinal } \\
\text { de todas las enfermedades: sacado de varios, y clasicos } \\
\text { authores, para bien de los pobres, y de los que tienen falta } \\
\text { de medicos ... reducido a tres libros, el primero de medicina, } \\
\text { el segundo de syruxia, con un apendix ... el tercero contiene } \\
\text { un cathalogo de los medicamentos ussuales ... (México, } \\
\text { 1712/1719). }\end{array}$ \\
\hline *Otro Historia poética & $\begin{array}{l}\text { Gautruche SJ, Pierre (1602-1681). L'Histoire poétique } \\
\text { pour l'intelligence des poëtes et autheurs anciens (Caen, } \\
\text { 1654). Historia poetica para la inteligencia de los Poetas, y } \\
\text { Autores antiguos, escrita en lengua francesa, traducida en } \\
\text { Idioma castellano por Pablo Vertejo (Madrid, 1719/1725). }\end{array}$ \\
\hline $\begin{array}{l}\text { * Otro Meditaciones de la } \\
\text { Vida de Cristo }\end{array}$ & $\begin{array}{l}\text { Lozano SJ, Pedro (1697-1752). Meditaciones sobre la vida } \\
\text { de Ntro. Señor Jeruchristo para cada día del año estendidas } \\
\text { en la lengua italiana por el P. Fabio Ambrosio Espínola... } \\
\text { (Madrid, 1748). } 2 \text { tomos }{ }^{31} \text {. }\end{array}$ \\
\hline $\begin{array}{l}\text { * Otro Diferencia entre lo } \\
\text { temporal y lo eterno }\end{array}$ & Cit. Nieremberg, Eusebio (1595-1658). \\
\hline *Otro Institución pastoral & Información insuficiente. \\
\hline Otro Sábado mariano & $\begin{array}{l}\text { Machoni SJ, Antonio (1672-1753). Dia virgineo, ó sabado } \\
\text { mariano que exhortando a la devocion de Maria Santíssima, } \\
\text { en su sagrado dia del sabado ofrece la piedad cristiana y }\end{array}$ \\
\hline
\end{tabular}

\footnotetext{
${ }^{30}$ En las Meditaciones espirituales del P. La Puente (Valladolid 1605), hay un capítulo titulado meditaciones de los pecados, pero no conocemos obra con ese título.

${ }^{31}$ Es una traducción que hace el P. Lozano del italiano al castellano. La versión príncipe en italiano fue de 1653 con varias ediciones posteriores.
}

180 Silvana M. Lovay. Las bibliotecas de las estancias jesuíticas... 166-200. 


\begin{tabular}{|c|c|c|}
\hline & & $\begin{array}{l}\text { dedica a la misma soberana reyna de los Angeles, gran Ma- } \\
\text { dre de Dios, y Abogada de los hombres (Córdoba, España, } \\
\text { 1733). }\end{array}$ \\
\hline & Uno Historia eclesiástica & $\begin{array}{l}\text { Gautruche SJ, Pierre (1602-1681). Historia eclesiástica. } \\
\text { Contiene la historia de los Papas en sus pontificados y las } \\
\text { cosas más memorables que pasaron en su tiempo, trad. del } \\
\text { francés por Pablo Vertejo... (Madrid, 1719). }\end{array}$ \\
\hline & Otros Discursos panegíricos & Información insuficiente ${ }^{32}$. \\
\hline & *2 tomos Vida de S. Ignacio & $\begin{array}{l}\text { Fluviá SJ, Francisco Javier (1699-1753). Vida de S. Igna- } \\
\text { cio de Loyola fundador de la Compañia de Je- } \\
\text { sus, enriquecida con las copiosas solidas noticias de los } \\
\text { Padres Jesuítas de Ambères, ordenada nuevamente y dividi- } \\
\text { da en ocho Libros (Barcelona, 1753) } 2 \text { tomos }^{33} \text {. }\end{array}$ \\
\hline & $\begin{array}{l}2 \text { tomos Vida de Juan Croi- } \\
\text { cet }\end{array}$ & Información insuficiente ${ }^{34}$. \\
\hline & $\begin{array}{l}4 \text { tomos de Meditaciones del } \\
\text { P. Lozano }\end{array}$ & Cit. Lozano SJ, Pedro (1697-1752). \\
\hline & $\begin{array}{l}\text { Uno de Avancino sobre la } \\
\text { Vida de Cristo }\end{array}$ & $\begin{array}{l}\text { Avancini SJ, Nicolás (1612-1686). Vida et doctrina Jesu } \\
\text { Christi ex quatuor evangelistis collecta: et in meditationum } \\
\text { materiam ad cíngulos totius anni dies distributa.(Viena, } \\
\text { 1665). }\end{array}$ \\
\hline & $\begin{array}{l}\text { *Otro de Cartas de S. Fran- } \\
\text { cisco Xavier }\end{array}$ & $\begin{array}{l}\text { Torsellino SJ, Orazio (1544-1599). S. P. Francisci Xaverii } \\
\text { e Soc. Iesv, epistolarum libri quatuor (Roma, } \\
\text { 1596/1607/1679/1681/1682/1711/1753). }\end{array}$ \\
\hline 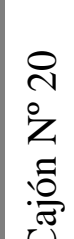 & $\begin{array}{l}* 9 \text { tomos en pasta del Des- } \\
\text { pertador cristiano }\end{array}$ & $\begin{array}{l}\text { Barcia y Zambrana, José de (1643-1695). Despertador } \\
\text { Christiano de sermones doctrinales : sobre particulares } \\
\text { assumptos ... dispuesto para que ... el pecador ... vença el } \\
\text { peligroso letargo de sus culpas, animandose à la peniten- } \\
\text { cia... (Granada, 1678/1691/1681/1684/1695/1697... 1727). }\end{array}$ \\
\hline & $\begin{array}{l}* 3 \text { tomos en } 4^{\circ} \text { sermones del } \\
\text { P. Diego Curado }\end{array}$ & $\begin{array}{l}\text { Curado, Diogo (i?). Sermoens do ... offecidos ao Espirito } \\
\text { Santo (Roma, 1719/1720). } 3 \text { tomos. }\end{array}$ \\
\hline & $\begin{array}{l}* 4 \text { tomos de a folio Castro } \\
\text { Palao }\end{array}$ & $\begin{array}{l}\text { Castro Palao SJ, Fernando (1581-1633). Conocemos cinco } \\
\text { obras, ninguna de cuatro tomos, las hay de } 1,3,6 \text { y } 7 \text {. Por lo } \\
\text { que pueden ser cuatro de la misma o de alguna de las otras } \\
\text { incompletas. }\end{array}$ \\
\hline
\end{tabular}

\footnotetext{
${ }^{32}$ Así comenzaron a titular sus obras varios autores como Juan de San Vicente (1658), Francisco de Lizana (1658), Juan Agustín Carreras Ramírez y Orta (1730)

${ }^{33}$ Varios escritores escribieron específicamente sobre San Ignacio, el primero fue Ribadeneira (Nápoles, 1572), Nieremberg (Madrid, 1631), Arcones (Granada, 1633), Lazcano (Granada, 1663), Ortiz (1679), García (Madrid, 1722), Mattos (Lisboa, 1718). Pero el que lo hizo en dos tomos fue Fluviá

${ }^{34}$ Quizás se refiera a alguna obra de Croiset SJ, Jean (1656-1738), de las que Sommervogel no solo señala 17, sino que como biografía marca la del P. Emile Régnault, pero recién publicada en 1888.
}

181 Silvana M. Lovay. Las bibliotecas de las estancias jesuíticas... 166-200. 


\begin{tabular}{|c|c|}
\hline *2 en folio de Lacroix & $\begin{array}{l}\text { Lacroix SJ, Claudius (1652-1714). Theologia moralis ante- } \\
\text { hac ex probatis... (Colonia, } \\
\text { 1707/1718/1729/1747/1754/1757) } 3 \text { tomos. }\end{array}$ \\
\hline $\begin{array}{l}\text { *8 tomos en } 4^{\circ} \text { sermones del } \\
\text { P. Manuel "consiencia" }\end{array}$ & $\begin{array}{l}\text { Ortigas SJ, Manuel (1609-1678). Tomo primero de las } \\
\text { obras del P. Manvel Ortigas de la Compañia de Iesvs... Da } \\
\text { Materia para sus Sermones, Platicas i Doctrinas, de los } \\
\text { Novisimos, Virtudes y Exemplos en sus seis Libros primeros } \\
\text { juntos, ya Impresos, que contienen... con tablas copiosas } \\
\text { diferentes... el indice general de las cosas notables de todos } \\
\text { los Libros, i Sermones va al fin de todo (Zaragoza, 1678). }\end{array}$ \\
\hline $\begin{array}{l}* 6 \text { tomos en } 4^{\circ} \text { la mocedad } \\
\text { desempeñada por el mismo } \\
\text { autor }\end{array}$ & $\begin{array}{l}\text { Ortigas SJ, Manuel (1609-1678). Corona eterna, esplica } \\
\text { la gloria accidental i esencial del cielo, de alma i cuerpo, da } \\
\text { avisos politicos cristianos a varios estados para no perderla } \\
\text { en vida y alcançarla en muerte : con discursos de los Evan- } \\
\text { gelios de Quaresma i Adviento i para sermones de Mision } \\
\text { con su indice i tabla / por el padre Manuel Ortigas de la } \\
\text { Compañia de Iesus... (Zaragoza, 1650). }\end{array}$ \\
\hline $\begin{array}{l}\text { *Un tomo de quarto Tribu- } \\
\text { nal Theologia y jurídico }\end{array}$ & Información insuficiente. \\
\hline $\begin{array}{l}\text { *Otro tomo en } 4^{\circ} \text { Itinerario } \\
\text { para párrocos }\end{array}$ & $\begin{array}{l}\text { Peña y Montenegro, Alonso de la (1596-1687). Itinerario } \\
\text { para Parochos de Indios, en que se tratan las materias mas } \\
\text { particulares, tocantes a ellos, para su buena administracion } \\
\text { (Madrid, 1668/1698/1678/1726). }\end{array}$ \\
\hline $\begin{array}{l}\text { *Otro de a folio Luz de las } \\
\text { verdades catholicas }\end{array}$ & $\begin{array}{l}\text { Martínez de la Parra SJ, Luis (1652-1701). Luz de verda- } \\
\text { des catolicas y explicacion de la doctrina christiana qve } \\
\text { siguiendo la costvmbre de la casa professa de la Compañia } \\
\text { de Jesvs de Mexico... (México, } \\
\text { 1691/1705/1717/1722/1737/1729/1747/1761). }\end{array}$ \\
\hline $\begin{array}{l}\text { *Otro juego de Lacroix, en } \\
\text { pergamino }\end{array}$ & Cit. Lacroix SJ, Claudius (1652-1714). \\
\hline *2 juegos de Calatayud & Información insuficiente $e^{35}$. \\
\hline $\begin{array}{l}\text { Un tomo de Lamentaciones } \\
\text { cristianas }\end{array}$ & Información insuficiente ${ }^{36}$. \\
\hline $\begin{array}{l}* 2 \text { tomos de Lozano, Histo- } \\
\text { ria del Paraguay }\end{array}$ & $\begin{array}{l}\text { Lozano SJ, Pedro (1697-1752). Historia de la Compañía de } \\
\text { Jesus en la Provincia del Paraguay... (Madrid, 1754-1755) } \\
2 \text { tomos. }\end{array}$ \\
\hline $\begin{array}{l}\text { *Un tomo del P. Mariano } \\
\text { sobre la Historia de España }\end{array}$ & $\begin{array}{l}\text { Mariana SJ, Juan de (1536-1624). Historia general de } \\
\text { España, (Toledo, 1592/1601/1608/1617/1623/1650...) }\end{array}$ \\
\hline *Otro de Escobar sobre los & Escobar y Mendoza SJ, Antonio de (1589-1669). Ad \\
\hline
\end{tabular}

${ }^{35}$ Del P. Pedro Antonio de Calatayud SJ (1659-1773) al menos se conocen 17 obras impresas entre 1731 y 1761 y de su homónimo Nicolás (1711-1767) una impresa en México en 1762.

${ }^{36}$ Podría ser Mateo Espinosa, quien con ese título publicó en 1667, pero no hemos dado con el ejemplar.

182 Silvana M. Lovay. Las bibliotecas de las estancias jesuíticas... 166-200. 
IHS. Antiguos Jesuitas en Iberoamérica ISSN: 2314-3908

\begin{tabular}{|c|c|}
\hline Evangelios & $\begin{array}{l}\text { Evangelia sanctorvm et Temporij Panegyricis moralibus } \\
\text { illustrati (Lyon, 1642-1649) } 12 \text { tomos. }\end{array}$ \\
\hline $\begin{array}{l}\text { Otro del P. Francisco sobre } \\
\text { el mismo asunto }\end{array}$ & Información insuficiente ${ }^{37}$. \\
\hline $\begin{array}{l}2 \text { del P. Diego Paez de Cris- } \\
\text { to figurado }\end{array}$ & $\begin{array}{l}\text { Báez SJ, Diego (1552-1647). Commentaria allegorica et } \\
\text { moralia de Christo figurato in Veteri Testamento (Valladolid, } \\
\text { 1632-1640). } 4 \text { tomos. }\end{array}$ \\
\hline *Uno Arte de Arquitectura & $\begin{array}{l}\text { Fray Lorenzo de San Nicolás (1593-1679). Arte y Vso de } \\
\text { architectura ... (Madrid, 1639-1665/1736). } 2 \text { tomos. }\end{array}$ \\
\hline $\begin{array}{l}* \text { Otro Mendoza sobre el } \\
\text { libro de los Reyes }\end{array}$ & $\begin{array}{l}\text { Mendoça SJ, Francisco de (1573-1626). Commentariorum } \\
\text { In IV Regum (Coímbra, 1621; Lisboa, 1624; Lyón, 1631) } 3 \\
\text { tomos. }\end{array}$ \\
\hline $\begin{array}{l}\text { *Otro sobre el sacrificio de } \\
\text { la Misa }\end{array}$ & Información insuficiente ${ }^{38}$. \\
\hline $\begin{array}{l}\text { Otro Rodriguez cuestiones } \\
\text { regulares }\end{array}$ & $\begin{array}{l}\text { Rodrigues, Manuel (1545-1613). Qvaestiones regvlares et } \\
\text { canonicae in qvibvs vtrivsque ivris... (Salamanca, 1598). } 4 \\
\text { tomos. }\end{array}$ \\
\hline $\begin{array}{l}\text { *Otro, luz de verdades cató- } \\
\text { licas }\end{array}$ & Cit. Martínez de la Parra SJ, Luis (1652-1701). \\
\hline $\begin{array}{l}* 2 \text { tomos en quarto, sermo- } \\
\text { nes de Vieyra }\end{array}$ & $\begin{array}{l}\text { Vieira SJ, Antonio (1608-1697). Sermones del P... (Ma- } \\
\text { drid, 1678/1680/1685/1711-1712). }\end{array}$ \\
\hline $\begin{array}{l}\text { *Uno Bonilla, Nombres y } \\
\text { atributos de Ntra. Sra. }\end{array}$ & $\begin{array}{l}\text { Bonilla, Alonso de (1570-1642). Nombres y atribvtos de la } \\
\text { impecable siempre Virgen María Señora Nuestra. En octa- } \\
\text { vas. Con otras rimas a diversos assumptus y glosas difíciles } \\
\text { (Baeza, 1624). }\end{array}$ \\
\hline $\begin{array}{l}* 3 \text { tomos de Rodriguez, } \\
\text { Ejercicios de perfección }\end{array}$ & Cit. Rodríguez SJ, Alonso (1538-1616). \\
\hline $\begin{array}{l}* 2 \text { los comentarios de Espa- } \\
\text { ña }\end{array}$ & $\begin{array}{l}\text { Bacallar y Sanna, Vincenso (1669-1726). Comentarios de } \\
\text { la guerra de España e historia de su Rey Phelipe V, el ani- } \\
\text { moso desde el principio de su regnado, hasta la paz general } \\
\text { del año } 1725 \text {, (Génova, 1726?) } 2 \text { tomos. }\end{array}$ \\
\hline
\end{tabular}
\begin{tabular}{l}
\hline${ }^{37}$ Podrían ser entre los jesuitas 1-Garau SJ, Francisco (1640-1701). Declamaciones Sacras, políticas y \\
morales sobre todos los Evangelios de la Quaresma (Valencia 1695/1698/ 1708). 2-Labata SJ, Francis- \\
co (1539-1631). Discursos morales sobre los Evangelios de los Santos (Valladolid, 1624). \\
${ }^{38}$ Podrían ser 1-Henao SJ, Gabriel de (1611-1704). De missae sacrificio divino atque tremendo. (Sal- \\
manca, 1658). 2-Tamburini SJ, Tommaso (1591-1675). De sacrifico Missae expedite celebrando (Pa- \\
lermo, 1649). 3-Tanner SJ. Mathias (1630-1692). Cruentum Christi Sacrificium, in incruento Missae \\
Sacrificio explicatum (Praga, 1666/1689/1710/1718/1756). 4-Negrón y Luna, Pedro Carlos (¿?). Exce- \\
lencias y frvtos del s. sacrificio de la missa. Diligencias necesarias para su cosecha... (Madrid, 1676). 5- \\
Titelmans, Franz (1502-1537). Expositione dei misteri e cerimonie, le quali si osservano nel santissimo \\
sacrificio della messa, (Venecia, 1548).
\end{tabular}

183 Silvana M. Lovay. Las bibliotecas de las estancias jesuíticas... 166-200. 
IHS. Antiguos Jesuitas en Iberoamérica ISSN: 2314-3908

\begin{tabular}{|c|c|}
\hline *Otro Vida del P. Montoya & $\begin{array}{l}\text { Xarque, Francisco (1607-1691). Vida prodigiosa del V. P. } \\
\text { Antonio Ruiz de Montoya (Zaragoza, 1662) }\end{array}$ \\
\hline$*$ Otro del oficio de los curas & $\begin{array}{l}\text { Noydens, Benito Remigio (1630-1685). Practica del oficio } \\
\text { de cvras, y confessores, y dotrina para penitentes... (Madrid, } \\
\text { 1650). }\end{array}$ \\
\hline $\begin{array}{l}\text { *Otro de pláticas de Calata- } \\
\text { yud }\end{array}$ & $\begin{array}{l}\text { Calatayud SJ, Pedro Antonio de (1659-1773). Juicio a los } \\
\text { sacerdotes; doctrina practica, y anatomía de sus concien- } \\
\text { cias, dispuesta en seis pláticas, que suele hacer el gremio } \\
\text { eclesiástico en sus misiones... (Pamplona, 1736/1754). }\end{array}$ \\
\hline $\begin{array}{l}\text { *Otro Palma Historia de la } \\
\text { Pasión }\end{array}$ & $\begin{array}{l}\text { Palma SJ, Luis de la (1560-1641). Historia de la Sagrada } \\
\text { Passion sacada de los qvatro evangelios. (Alcalá, 1624). }\end{array}$ \\
\hline $\begin{array}{l}\text { *Otro Práctica del Catecis- } \\
\text { mo Romano }\end{array}$ & $\begin{array}{l}\text { Nieremberg SJ, Juan Eusebio (1595-1658). Practica del } \\
\text { catecismo romano, y doctrina christiana, sacada principal- } \\
\text { mente de los catecismos de Pio Vy Clemente VIII... (Ma- } \\
\text { drid, 1640). }\end{array}$ \\
\hline Otro Instituciones cristianas & Información insuficiente. \\
\hline $\begin{array}{l}* 2 \text { Nieremberg, uno Dife- } \\
\text { rencia de lo Temporal y lo } \\
\text { Eterno y otro sobre el apre- } \\
\text { cio de la divina gracia }\end{array}$ & $\begin{array}{l}\text { Nieremberg SJ, Eusebio (1595-1658). Del aprecio y estima } \\
\text { de la divina gracia (Madrid, 1638). }\end{array}$ \\
\hline $\begin{array}{l}\text { *Otro Relación Historial de } \\
\text { los Chiquitos }\end{array}$ & Cit. Fernandez SJ, Joan Patricio (1667-1733). \\
\hline $\begin{array}{l}\text { Otro de la Vida de S. Igna- } \\
\text { cio }\end{array}$ & Información insuficiente ${ }^{39}$. \\
\hline $\begin{array}{l}\text { *Otro de la Vida del P. Mes- } \\
\text { trello }\end{array}$ & $\begin{array}{l}\text { Nieremberg SJ, Juan Eusebio (1595-1658). Vida del di- } \\
\text { choso y venerable Padre Marcelo Francisco Mastrilli, de la } \\
\text { Compañia de Iesus, que murió en el Iapon por la Fe de } \\
\text { Christo, sacada de los procesos Autenticos de su vida y } \\
\text { muerte... (Madrid, 1640). }\end{array}$ \\
\hline $\begin{array}{l}\text { *Otro Avisos de Santa Tere- } \\
\text { sa }\end{array}$ & Cit. Andrade SJ, Alonso de (1590-1672). \\
\hline $\begin{array}{l}\text { *Otro Censura de la Elo- } \\
\text { cuencia }\end{array}$ & $\begin{array}{l}\text { Ledesma, Gonzalo Pérez de (¿?). Censvra de la eloqvencia } \\
\text { para calificar svs obras, y señaladamente las del pvlpito } \\
\text { (Zaragoza, 1648). }\end{array}$ \\
\hline$*$ Otro Elogio de coadjutores & $\begin{array}{l}\text { Oviedo SJ, Juan Antonio de (1670-1757). Elogios de mu- } \\
\text { chos hermanos coadjutores de la Compañia de Jesus, que en } \\
\text { las quatro partes del Mundo han florecido con grandes } \\
\text { créditos de Santidad. Recogidos de muchos autores (Méxi- } \\
\text { co, 1755). }\end{array}$ \\
\hline
\end{tabular}

39 Pueden ser varios autores como Ribadeneira (Nápoles, 1572), Nieremberg (Madrid, 1631), Arcones (Granada, 1633), Lazcano (Granada, 1663), Ortiz (1679), García (Madrid, 1722), Mattos (Lisboa, 1718).

184 Silvana M. Lovay. Las bibliotecas de las estancias jesuíticas... 166-200. 
IHS. Antiguos Jesuitas en Iberoamérica ISSN: 2314-3908

\begin{tabular}{|c|c|c|}
\hline & *Otro de Belarmino & Información insuficiente ${ }^{40}$. \\
\hline \multirow{10}{*}{ 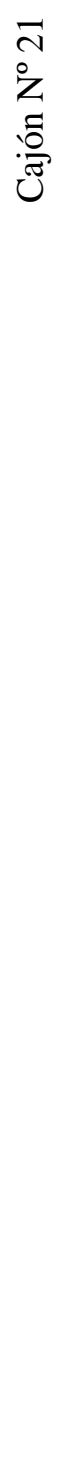 } & *Obra del P. Sánchez & Información insuficiente ${ }^{41}$. \\
\hline & $\begin{array}{l}\text { *Un tomo Aleseum Specu- } \\
\text { lum Parrocorum }\end{array}$ & $\begin{array}{l}\text { Abreu SJ, Sebastián de (1594-1674). Institvtio parochi sev } \\
\text { Specvlvm Parochorvm in qvo parochi, et omnes animarvm } \\
\text { cvram exercentes... (Evora, 1665/1668/1724/1734/1761). }\end{array}$ \\
\hline & $\begin{array}{l}* 2 \text { juegos de la Biblia y } \\
\text { concordancias }\end{array}$ & Información insuficiente ${ }^{42}$. \\
\hline & $\begin{array}{l}3 \text { tomos en pasta y } 2 \text { en per- } \\
\text { gamino }\end{array}$ & Información insuficiente. \\
\hline & $\begin{array}{l}2 \text { tomos Vida de Phelipe II } \\
\text { en Italiano }\end{array}$ & $\begin{array}{l}\text { Leti, Gregorio (1630-1701). Vita del Catolico Re Filipo II, } \\
\text { monarca delle Spagne (Colonia, 1679) } 2 \text { tomos. }\end{array}$ \\
\hline & *Un Diccionario de Sobrino & $\begin{array}{l}\text { Sobrino, Francisco (¿?-1732?,). Diccionario nuevo de las } \\
\text { Lenguas española y francesa, (Bruselas, 1705) } 2 \text { tomos. }\end{array}$ \\
\hline & $\begin{array}{l}\text { *Un tomo del P. Francisco } \\
\text { Año Glorioso }\end{array}$ & $\begin{array}{l}\text { Franco SI, Antonio (1662-1732). Annus gloriosus Societa- } \\
\text { tis Jesu in Lusitania, complectens sacras memorias illus- } \\
\text { trium virorum, qui virtutibus ... societatem Jesu ... exorna- } \\
\text { runt succincta narratione congestas a.... (Viena, 1720). }\end{array}$ \\
\hline & $\begin{array}{l}\text { *3 tomos de Historia del } \\
\text { Paraguay por el P. Charle- } \\
\text { voix }\end{array}$ & $\begin{array}{l}\text { Charlevoix SJ, Pierre-François-Xavier de (1682-1761). } \\
\text { Histoire du Paraguay (París, 1756) } 3 \text { tomos }{ }^{43} \text {. }\end{array}$ \\
\hline & $\begin{array}{l}* 2 \text { tomos de la historia de la } \\
\text { isla de Sto. Domingo }\end{array}$ & $\begin{array}{l}\text { Charlevoix SJ, Pierre-François-Xavier de (1682-1761). } \\
\text { Histoire de l'Isle Espagnole ou de S. Domingue (París, 1730- } \\
\text { 1731) } 2 \text { tomos. }\end{array}$ \\
\hline & $\begin{array}{l}* 2 \text { tomos de sermones } \\
\text { domésticos del P. Oliva }\end{array}$ & $\begin{array}{l}\text { Oliva SJ, Juan Paulo (1600-1681). Sermoni domestici detti } \\
\text { priuatamente nelle Case Romane della Compagnia di Giesu. } \\
(\text { Roma, 1670-1682) }\end{array}$ \\
\hline
\end{tabular}

${ }^{40}$ Roberto Belarmino SJ (1542-1621). Escribió una docena de libros.

${ }^{41} \mathrm{Si}$ es jesuita pueden ser Gaspar Sánchez (1553/1554-1625), Tomás Sánchez (1550-1610), Ángel Sánchez Aliofrín (1727-1803), Juan Sánchez Baquero (1545-1619), todos con varias obras cada uno.

${ }^{42}$ Podrían ser: 1-Zamora SJ, Gaspar de (1546-1621). Concordantiae Sacrorum Bibliorum quae sunt supra mensam Bibliothecae (Roma, 1627). 2-Calascio OF, Mario de (1550-1620). Concordantiae Sacrorum Bibliorum hebraicorum in quibus Chaldaicae, etiam Librorum Esdrae, \& Danielis suo loco inseruntur... (1621/1747/1749) 2 tomos. 3-Broickwy a Koninckstein OFM, Antonius (¿1470?-1541). Concordantiae breuiores omnium ferme materiarum ex Sacris Bibliorum libris (Salamanca, 1552). 4-Plantin, Christophe (ed.) (1520-1589). Concordantia bibliorum vtriusque Testamenti, veteris et novi, perfectae et integrae, quas re vera Maiores appelare possis ... (Salamanca, 1581).

${ }^{43}$ Originalmente la obra de Charlevoix se compone de tres tomos escritos en francés. El P. Muriel tradujo la obra al latín agregando un tomo que continúa hasta la expulsión (Historia Paraguajensis Petri Francisci-Xaverii de Charlevoix, ex Gallico Latina cum animadversionibus et supplemento (Venecia, 1779) y el P. Hernández la publica en 6 tomos en castellano entre 1910 y 1919.

${ }^{44}$ En realidad fueron 10 tomos publicados en Roma, entre 1670 y 1682.

185 Silvana M. Lovay. Las bibliotecas de las estancias jesuíticas... 166-200. 


\begin{tabular}{|c|c|}
\hline $\begin{array}{l}\text { *Un tomo cuaresma del P. } \\
\text { Ealino }\end{array}$ & $\begin{array}{l}\text { Calino SJ, César (1670-1749). Quaresimale di Cesare Ca- } \\
\text { lino della Compagnia di Gesú, (Venecia, 1731). }\end{array}$ \\
\hline $\begin{array}{l}* 5 \text { tomos de Severis el Cris- } \\
\text { tiano y Cura Instruido }\end{array}$ & $\begin{array}{l}\text { Segneri SJ, Paolo (1624-1694). Il cristiano instruito nella } \\
\text { sua legge; ragionamenti morali (Florencia, 1686/1687) }{ }^{45} . \text { Il } \\
\text { parroco istruito. Opera in cui si dimostra a qualsisia curato } \\
\text { nouello il debito, che lo stringe, e la via da tersi } \\
\text { nell'adempirlo data a in luce da... (Nápoles, } 1693)^{46} .\end{array}$ \\
\hline $\begin{array}{l}\text { *11 tomos en pasta por } \\
\text { Maimberg sobre Herejías }\end{array}$ & $\begin{array}{l}\text { Maimbourg SJ, Louis (1610-1686). Les histoires du Sieur } \\
\text { Maimbourg (París, 1686-1687). } 14 \text { Tomos }^{47} \text {. }\end{array}$ \\
\hline $\begin{array}{l}\text { *3 tomos de la Geografia } \\
\text { anciano moderna e histórica }\end{array}$ & Información insuficiente ${ }^{48}$. \\
\hline *7 tomos de Graveson & $\begin{array}{l}\text { Graveson, Ignacio Jacinto Amat de (1670-1733). Opera } \\
\text { Omnia. Hucusque sparsim edita, nunc veto in septem tomos } \\
\text { tributa (Venecia, 1750). }\end{array}$ \\
\hline *Un tomo de Prosodia & $\begin{array}{l}\text { Alvares SJ, Manuel (1526-1583). De institutione gramma- } \\
\text { tica libri tres (Lisboa, 1572) }\end{array}$ \\
\hline $\begin{array}{l}* 23 \text { tomos de Cartas Edifi- } \\
\text { cantes }\end{array}$ & $\begin{array}{l}\text { Davin SJ, Diego (1704-1760). Cartas edificantes, y curiosas, } \\
\text { escritas de las missiones estrageras, por algunos missioneros } \\
\text { de la Compañía de Jesus traducidas del idioma francés por } \\
\text { el P... (Madrid, 1753-1757) } 16 \mathrm{v} \text {. }\end{array}$ \\
\hline $\begin{array}{l}\text { *Un tomo manuscrito consi- } \\
\text { deraciones espirituales }\end{array}$ & Información insuficiente ${ }^{50}$. \\
\hline $\begin{array}{l}\text { Otro dicho Ejercicios de } \mathrm{S} \text {. } \\
\text { Ignacio por el P. Ignacio } \\
\text { Dierstino }\end{array}$ & $\begin{array}{l}\text { Diertins SJ, Ignacio (Joseph) (1626-1700). Exercitia Spiri- } \\
\text { tualia S. P. Ignatuu Loyolae, cum sensu eorumdem explana- } \\
\text { to }(\text { París, 1693/1696) }\end{array}$ \\
\hline *Otro Busembaum & Cit. Busenbaum SJ, Hermann (1600-1668). \\
\hline $\begin{array}{l}* 3 \text { tomos crevier sobre la } \\
\text { Historia de Titolivio }\end{array}$ & $\begin{array}{l}\text { Jean-Baptiste-Louis Crevier (1735-1742). T. Livii historia- } \\
\text { rum libri qui extant... (Venecia 1751). }\end{array}$ \\
\hline *Un tomito meditación de & $\begin{array}{l}\text { Avancini SI, Nicola (1611-1686), Vita et doctrina Jesu } \\
\text { Christi: ex quatuor Euangelistis collecta et in meditationum }\end{array}$ \\
\hline \multicolumn{2}{|c|}{$\begin{array}{l}{ }^{45} \text { La obra fue traducida al castellano por don Juan de Espinola Baeza y publicada en Barcelona en } 1693 \\
\text { en } 3 \text { tomos. }\end{array}$} \\
\hline \multicolumn{2}{|c|}{$\begin{array}{l}{ }^{46} \text { La obra (El cvra instruido...) fue traducida al castellano por don Juan de Espinola Baeza y publicada } \\
\text { en Madrid en } 1713 \text { y Barcelona en } 1724\end{array}$} \\
\hline \multicolumn{2}{|c|}{$\begin{array}{l}{ }^{48} \text { Así lo cita Fraschini pero no lo hemos hallado: Lima, Luis Cayetano de (1671-1757). Geografia anti- } \\
\text { gua, moderna e histórica de Europa (Lisboa, 1736) Tres tomos, cuatro, en francés. }\end{array}$} \\
\hline \multicolumn{2}{|c|}{$\begin{array}{l}{ }^{49} \text { De institutione grammatica libri tres son tres tomos: De etymologia, De syntaxi y De Prosodia sive } \\
\text { Institutionum linguae latinae. Múltiples ediciones. }\end{array}$} \\
\hline \multicolumn{2}{|c|}{$\begin{array}{l}50 \mathrm{Si} \text { es un manuscrito muy probablemente haya sido escrito por un profesor del Coleg } \\
{ }^{51} \text { Esta obra fue publicada en castellano por el P. Domingo Muriel en Faenza en } 1772 .\end{array}$} \\
\hline
\end{tabular}

186 Silvana M. Lovay. Las bibliotecas de las estancias jesuíticas... 166-200. 
IHS. Antiguos Jesuitas en Iberoamérica ISSN: 2314-3908

Vol. 5 no 2

julio-diciembre 2017

\begin{tabular}{|c|c|}
\hline Avancini & materiam singulos totius anni dies distributa. Colonia, 1744. \\
\hline $\begin{array}{l}* 2 \text { tomitos Discursos sobre } \\
\text { la Historia Unibersal por } \mathrm{Sr} \text {. } \\
\text { Borbet }\end{array}$ & $\begin{array}{l}\text { Jacques Bénigne Bossuet (1627-1704). Discours sur } \\
\text { l'histoire universelle (Paris, 1681). }\end{array}$ \\
\hline $\begin{array}{l}5 \text { tomos de licencia de Es- } \\
\text { paña (falta el } 2^{\circ} \text { ) }\end{array}$ & Información insuficiente. \\
\hline $\begin{array}{l}7 \text { tomos de licensias de la } \\
\text { Gran Bretaña (falta } 1^{\circ} \text { ) }\end{array}$ & Información insuficiente. \\
\hline $\begin{array}{l}10 \text { tomitos colino "Leccion } \\
\text { Espiritual" }\end{array}$ & $\begin{array}{l}\text { Colin SJ, Francisco (1592-1660). Sermón. Que mando im- } \\
\text { primir el Illustrisimo y Reverendissimo S. D. Fray Miguel } \\
\text { García Serrano Arçobispo de Manila del consejo de su Ma- } \\
\text { gestad... predicado por el Padre Francisco Colin (Manila, } \\
1628)^{52} \text {. }\end{array}$ \\
\hline $\begin{array}{l}\text { Y otros } 6 \text { mas del mismo } \\
\text { autor sobre distintas mate- } \\
\text { rias }\end{array}$ & Información insuficiente ${ }^{53}$. \\
\hline $\begin{array}{l}6 \text { tomos en italiano del Dic- } \\
\text { cionario portátil que compu- } \\
\text { so en francés el Sr. Labocato }\end{array}$ & $\begin{array}{l}\text { Ladvocat, Jean-Baptiste (1709-1765). Dictionnaire histo- } \\
\text { rique-portatif, contenant l'historie des patriarches, des prin- } \\
\text { ces hebreux, des empereurs, des rois et des grands capitai- } \\
\text { nes... (Paris, 1761). }\end{array}$ \\
\hline $\begin{array}{l}\text { *Dos tomos del P. Dionisio } \\
\text { Potabio Rationarium tempo- } \\
\text { rum }\end{array}$ & $\begin{array}{l}\text { Petau SJ, Dionisio (1583-1652). Rationarivm temporvm in } \\
\text { partes dvas (Paris, 1633) } 2 \text { tomos. }\end{array}$ \\
\hline $\begin{array}{l}\text { Un tomo de verdades cat- } \\
\text { holicas }\end{array}$ & Cit. Martínez de la Parra SJ, Luis (1652-1701). \\
\hline $\begin{array}{l}\text { *Dos tomos de Calatayud } \\
\text { misión y sermones }\end{array}$ & $\begin{array}{l}\text { Calatayud SJ, Pedro Antonio de (1659-1773). Missiones y } \\
\text { Sermones del P... (Madrid, 1754). } 2 \text { tomos. }\end{array}$ \\
\hline $\begin{array}{l}* \text { Cuatro tomos Nueva flo- } \\
\text { resta por el P. Manuel Ber- } \\
\text { nardes }\end{array}$ & $\begin{array}{l}\text { Bernardes, Manuel (1644-1710). Nova Floresta, ou silva } \\
\text { de vários apophtegmas e ditos sentenciosos, espirituais e } \\
\text { morais, com reflexões em que o útil da doutrina se acom- } \\
\text { panha com o vário da erudição, assim divina como humana }\end{array}$ \\
\hline \multicolumn{2}{|c|}{$\begin{array}{l}52 \text { Es muy posible que se refieran a esta obra de } 11 \text { folios. } \\
{ }^{53} \text { Los siguientes títulos cita Sommervogel: In festi annui institutione, ob liberatam anno } 1629 \text { classem } \\
\text { Hispanicam, ab insidiis Hollandorum (S/L y S/F). In pompa funebri quam civitas Manilensis instituit in } \\
\text { obitu Hispaniarum et Indiarum Principis Balthasaris (Manila, 1649). Vida, hechos y doctrina del venera- } \\
\text { ble hermano Alonso Rodriguez, religioso de la Compañáa de Jesús (Madrid, 1652). Labor evangelica, } \\
\text { ministerios apostólicos de los obreros de la Compañia de Iesus, fundacion y progressos de su provincia } \\
\text { en las islas Filipinas / historiados por el padre Francisco Colin, provincial de la misma compañia; parte } \\
\text { primera sacada de los manuscriptos del padre Pedro Chirino (Madrid, 1663). India Sacra, hoc est, suppe- } \\
\text { tiae sacrae ex utraque India in Europea, pro interpretatione facili... (Madrid, 1666). Quatro devotissimas } \\
\text { meditaciones que dexó escritas, en que con mucha eficacia comprehende la doctrina de las quatro sema- } \\
\text { nas de los exercicios de N. P. S. Ignacio. Este último Sommervogel lo cita de Murillo Velarde, quien } \\
\text { también dice escribió un librito de Meditaciones, Otro sobre Miserere y una Historia de Japón. }\end{array}$} \\
\hline
\end{tabular}

187 Silvana M. Lovay. Las bibliotecas de las estancias jesuíticas... 166-200. 
IHS. Antiguos Jesuitas en Iberoamérica ISSN: 2314-3908

Vol. 5 no 2

julio-diciembre 2017

\begin{tabular}{|c|c|c|}
\hline & & (Lisboa, 1708-1728) 5 tomos. \\
\hline \multirow{2}{*}{ 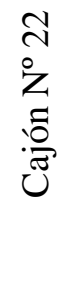 } & $\begin{array}{l}\text { *Un tomo tesauro de la Doc- } \\
\text { trina Cristiana de Furlot }\end{array}$ & $\begin{array}{l}\text { Furlot (o Fierlot) Thesaur. De Doctrina Christiana (Tesoro } \\
\text { de la doctrina cristiana) }{ }^{54} \text {. }\end{array}$ \\
\hline & $\begin{array}{l}\text { *Un tomo Magnum Specu- } \\
\text { lum Eccemplorum }\end{array}$ & $\begin{array}{l}\text { Major, Joanes (1467-1550). Magnum speculum exemplo- } \\
\text { rum, ex plvsquam octoginta auctoribus, pietate, doctrina, et } \\
\text { antiqvitate ... variisque (Colonia, } \\
\text { 1510/1513/1605/1607/1618/1624/1653). }\end{array}$ \\
\hline & $\begin{array}{l}\text { *2 tomos Ytinerario Historia } \\
\text { por el P. Alonso de Andrade }\end{array}$ & $\begin{array}{l}\text { Andrade SJ, Alonso López de (1590-1672). Itinerario his- } \\
\text { torial que deve gvardar el hombre para caminar al cielo } \\
\text { (Madrid, 1648/1657/1670/1684) } 2 \text { tomos. }\end{array}$ \\
\hline & $\begin{array}{l}* 2 \text { tomos de Estefano de } \\
\text { menachio el } 2^{\circ} \text { y el } 3^{\circ} \text { (falta } \\
\text { el } 1^{\circ} \text { ) }\end{array}$ & $\begin{array}{l}\text { Menochio SJ, Giovanni Stefano }(1575-1655) \text {. Delle stvore } \\
\text { overo trattenimenti ervditi del padre... tessuti di varia erudi- } \\
\text { tione sacra, morale e profana ... (Roma, 1653- } \\
1654 / 1662 / 1675 / 1689 / 1701) 6 \text { tomos }^{55} \text {. }\end{array}$ \\
\hline & $\begin{array}{l}\text { *4 tomos del P. Viva } 2 \text { de } \\
\text { teología moral y dos sobre } \\
\text { proposiciones condenadas }\end{array}$ & $\begin{array}{l}\text { Vivas SJ, Domenico (1647-1726). Cursus theologico- } \\
\text { moralis... (Padua, 1723/1726/1737) } 8 \text { Tomos. Opera omnia } \\
\text { theologico-moralia... (Ferrara, 1757). } 8 \text { Tomos }^{56}\end{array}$ \\
\hline & $\begin{array}{l}* \mathrm{El} 2^{\circ} \text { tomo del P. Carlom- } \\
\text { brogio sobre el Exercicio de } \\
\text { la buena muerte }\end{array}$ & $\begin{array}{l}\text { Cattaneo SJ, Carlo Ambrogio (1645-1705). Esercizio della } \\
\text { buona norte... (Milán, 1713). }\end{array}$ \\
\hline & $\begin{array}{l}\text { *Un tomo Dias sagrados y } \\
\text { geniales en la canonización } \\
\text { de S. Francisco de Borja }\end{array}$ & $\begin{array}{l}\text { Fomperosa y Quintana SJ, Ambrosio (1639-1689). Dias } \\
\text { sagrados, y geniales, celebrados en la canonizacion de S. } \\
\text { Francisco de Borja. Por el colegio imprerial de la Compañ- } \\
\text { ia de Iesvs de Madrid y la academia... (Madrid, 1672). }\end{array}$ \\
\hline & $\begin{array}{l}\text { *Otro instrucciones cristia- } \\
\text { nas sobre las dominicas del } \\
\text { año }\end{array}$ & $\begin{array}{l}\text { Rajas SJ, Martin (1664-1742). Instrucciones christianas, } \\
\text { sobre las dominicas de el año (Madrid, 1721). }\end{array}$ \\
\hline & $\begin{array}{l}\text { *Un tomo Arte bocabulario } \\
\text { de la lengua Guaraní }\end{array}$ & $\begin{array}{l}\text { Ruiz de Montoya SJ, Antonio (1585-1652). Arte y vocabu- } \\
\text { lario de la lengua guaraní (Madrid, 1640) }\end{array}$ \\
\hline & $\begin{array}{l}\text { *Otro Superior Instruido por } \\
\text { el P. Antonio Machoni }\end{array}$ & Cit. Machoni SJ, Antonio (1672-1753). \\
\hline & *Otro Conquista Espiritual & Ruiz de Montoya SJ, Antonio (1585-1652). Conquista \\
\hline
\end{tabular}

${ }^{54}$ Esta obra solo la hemos encontrado citada de esta manera en Luis Belluga y Moncada (1709). Memorial del doctor don Luis Belluga Obispo de Cartagena al rey Phelipo Quinto sobre las materias pendientes con la Corte de Roma, y expulsión del Nuncio de Su Santidad de los Reynos de España. Murcia, p. 80

${ }^{55}$ Suponemos que es esta obra pues el P. Menochio escribió varios libros, de los cuales uno son dos tomos y este es de seis tomos.

${ }^{56} \mathrm{Al}$ referirse a "teología moral" pueden ser estas dos obras. En cuanto a "proposiciones condenadas", el P. Viva no tiene título alguno con estas palabras. Si hay una obra de Martín de Torrecilla publicada en 1688.

${ }^{57}$ El Vocabulario de la lengua guaraní compuesto por el P. Antonio Ruiz, fue revisado y reeditado en la imprenta de la reducción de Santa María la Mayor en 1722.

188 Silvana M. Lovay. Las bibliotecas de las estancias jesuíticas... 166-200. 


\begin{tabular}{|c|c|}
\hline del Paraguay & $\begin{array}{l}\text { espiritual hecha por los religiosos de la Compañía de Jesús } \\
\text { en las Provincias del Paraguay, Paraná, Uruguay y Tape } \\
\text { (Madrid, 1639) }\end{array}$ \\
\hline *Otro principios de cirugía & $\begin{array}{l}\text { Ayala, Jerónimo de (1632-1702). Principios de cirvgía, } \\
\text { vtiles y provechosos para que puedan aprovecharse los } \\
\text { principiantes en esta Facultad... (Madrid, } \\
\text { 1672/1693/1705/1716). }\end{array}$ \\
\hline $\begin{array}{l}\text { *Otro Historia del Gran } \\
\text { Chaco por el P. Antonio } \\
\text { Machoni }\end{array}$ & $\begin{array}{l}\text { Lozano SJ, Pedro (1697-1752). Descripcion chorográfica } \\
\text { del terreno, ríos, arboles y animales de las dilatadissimas } \\
\text { Provincias del gran Chaco Gualamba ... (Córdoba-España, } \\
1733)^{58} \text {. }\end{array}$ \\
\hline $\begin{array}{l}\text { *Bocabulario de la lengua } \\
\text { quichua }\end{array}$ & Información insuficiente ${ }^{59}$. \\
\hline $\begin{array}{l}* 2 \text { tomos de Nieremberg, } \\
\text { uno que trata sobre la her- } \\
\text { mosura de Dios y otro Dife- } \\
\text { rencia entre lo temporal y lo } \\
\text { eterno }\end{array}$ & $\begin{array}{l}\text { Nieremberg SJ, Juan Eusebio (1595-1658). De la hermo- } \\
\text { sura de Dios y su amabilidad por las infinitas perfecciones } \\
\text { del ser divino... (Madrid, 1641). }\end{array}$ \\
\hline $\begin{array}{l}\text { *Un tomo de Echevera, } \\
\text { Pláticas Doctrinales }\end{array}$ & $\begin{array}{l}\text { Echeverz OM, Francisco Miguel (1672-1745). Platicas } \\
\text { doctrinales ordenadas, y añadidas nuevamente por su aut- } \\
\text { hor... (Madrid, 1728/1735/1740). }\end{array}$ \\
\hline $\begin{array}{l}\text { *Un tomo de Cathecismo } \\
\text { por el P. Murillo }\end{array}$ & $\begin{array}{l}\text { Murillo Velarde SJ, Pedro (1696-1753). Catecismo o ins- } \\
\text { truccion christiana, en que se explican los mynisterios de } \\
\text { nuestra Santa Fe y se exhorta... (Madrid, 1752). }\end{array}$ \\
\hline $\begin{array}{l}\text { *Un tomo Apologia a favor } \\
\text { de las notas que el P. Señeri } \\
\text { hizo sobre la vida interior } \\
\text { del IImo. Sr. Juan de Pela- } \\
\text { fox }\end{array}$ & $\begin{array}{l}\text { Marín SJ, Matías (1654-1725). Apología del Lic. ... } \\
\text { a favor de vnas notas, qve consvltado en Roma el reveren- } \\
\text { diddimo Padre Señeri, de la Compañía de Jesvs, predicador } \\
\text { y... hizo sobre la vida interior escrita de el ilustrissimo se- } \\
\text { ñor D. Jvan de Palafox. Respuesta al reverendissimo padre } \\
\text { fray Jvan de la Anunciación... (Valencia, 1695). }\end{array}$ \\
\hline $\begin{array}{l}\text { *Otro de Apología de la } \\
\text { Verdad contra varias impos- } \\
\text { turas }\end{array}$ & $\begin{array}{l}\text { Jaramillo SJ, Antonio (1648-1700). Apologia, la Verdad } \\
\text { contra varias impostvras y acvsaciones pvblicas compvesta } \\
\text { por... (Madrid, 1697). }\end{array}$ \\
\hline $\begin{array}{l}* 3 \text { tomos de Historia del } \\
\text { Pueblo de Dios }\end{array}$ & $\begin{array}{l}\text { Berryer SJ, Isaac Joseph (1697-1758). Historia del Pueblo } \\
\text { de Dios desde su origen hasta el nacimiento del Messias... / } \\
\text { escrita en el idioma francés por el P. Isaac Joseph Berru- }\end{array}$ \\
\hline
\end{tabular}

\footnotetext{
${ }^{58}$ En realidad lo que hizo el P. Machoni, como procurador a Europa fue publicarle la obra al P. Lozano. Por eso figura en la portada y el que inventarió, lo confundió con el autor.

${ }^{59}$ A partir del Concilio Limense aparecen varias obras sobre Arte y "Vocabulario" en quichua. La primera que se publica con varias ediciones es la de Francisco del Canto (Sevilla, 1603 y Lima, 1604) que algunos atribuyen al P. Barzana. Luego vienen varios otros autores. Podrían ser entre los jesuitas 1-Diego González Holguin SJ (1553-1617). Vocabulario de la Lengva General de todo el Perv llamada Lengva Qquichua o del Inca. (Lima, 1608). 2-Diego de Torres Rubio SJ (1548-1638). Arte y vocabulario en la lengua general del Perú, llamada quichua y en la lengua español (Lima, 1603).
} 


\begin{tabular}{|c|c|}
\hline & $\begin{array}{l}\text { yer...; y traducida al español por el P. Antonio Espinosa } \\
\left(\text { Madrid, 1746/1751) }{ }^{60} .\right.\end{array}$ \\
\hline $\begin{array}{l}\text { *Un tomo Pláticas de Cala- } \\
\text { tayud para sacerdotes }\end{array}$ & $\begin{array}{l}\text { Calatayud SJ, Pedro Antonio de (1659-1773). Juizio de } \\
\text { los sacerdotes, doctrina practica, y anatomia de sus con- } \\
\text { ciencias, dispuesta en seis platicas, que suele hazer al gre- } \\
\text { mio eclesiastico en sus missiones, y una instruccion que dà à } \\
\text { un ilustrissimo señor obiso... (Valencia, 1736). }\end{array}$ \\
\hline $\begin{array}{l}\text { *Un tomo Prasis cathechéti- } \\
\text { ca por el P. Matías Heim- } \\
\text { bach }\end{array}$ & $\begin{array}{l}\text { Heimbach SJ, Mathias (1666-1747). Praxis catechetica, } \\
\text { sive manuductio pro instruentis rudibus elementa fidei prac- } \\
\text { tice explanans... (Paris, 1702/1707/1755). }\end{array}$ \\
\hline Otro verdades eternas & $\begin{array}{l}\text { Rosignolo SJ, Carlo Gregorio (1631-1707). Verita eterne } \\
\text { esposte in lezioni... (Milán, 1688). }\end{array}$ \\
\hline $\begin{array}{l}\text { *Dos tomos de Murillo que } \\
\text { tratan de Derecho Canónico }\end{array}$ & $\begin{array}{l}\text { Murillo Velarde SJ, Pedro (1696-1753). Cursus Iuris Ca- } \\
\text { nonici hispani et indici (Madrid, 1741/1743/1763/1791). } 2 \\
\text { tomos. }\end{array}$ \\
\hline $\begin{array}{l}\text { *3 tomos de Melendes The- } \\
\text { soro de las Indias }\end{array}$ & $\begin{array}{l}\text { Meléndez OP, Juan (1633-1710). Tesoros verdaderos de } \\
\text { las Yndias En la Historia de la gran Prouincia de San Iuan } \\
\text { Bavtista del Perv De el Orden de Predicadores.... (Roma, } \\
\text { 1681-1682). } 3 \text { volúmenes. }\end{array}$ \\
\hline $\begin{array}{l}\text { *2 tomos de Torquemada } \\
\text { Monarquia Indiana }\end{array}$ & $\begin{array}{l}\text { Torquemada OFM, Juan de (¿1557?-1624). Los veynte y } \\
\text { vn libros Rituales y Monarchia Yndiana con el origen y gue- } \\
\text { rras de los Yndios Occidentales, de sus poblaçones, descu- } \\
\text { brimientos, conquista, conversión y otras cosas maravillosas } \\
\text { de la mesma tierra... (Sevilla, 1615/1723). } 3 \text { tomos. }\end{array}$ \\
\hline $\begin{array}{l}* 3 \text { tomos de Casani Varones } \\
\text { Ilustres }\end{array}$ & $\begin{array}{l}\text { Cassani SJ, José (1673-1750). Glorias del segundo siglo de } \\
\text { la Compañía de Jesús, dibuxadas en las vidas, y elogios de } \\
\text { algunos de sus varones ilustres en virtud, letras, y zelo de las } \\
\text { almas que han florecido desde el año de 1640, primero del } \\
\text { segundo siglo, desde la aprobacion de la Religion (Madrid, } \\
\text { 1734-1736). } 3 \text { tomos. }\end{array}$ \\
\hline $\begin{array}{l}\text { *Un tomo Cielo estrellado } \\
\text { de Maria. }\end{array}$ & $\begin{array}{l}\text { Alloza SJ, Juan (1597-1666). Cielo estrellado de mil y veyn- } \\
\text { te y dos exemplos de Maria. Paraiso espiritval y tesoro de } \\
\text { favores, y regalos con qve esta gran señora ha fauorecido a } \\
\text { los que se acogen a su proteccion, y amparo (Madrid, 1654). }\end{array}$ \\
\hline $\begin{array}{l}\text { *Un tomo de la prosecución } \\
\text { de la Misión de Cochinchina }\end{array}$ & $\begin{array}{l}\text { Obra colectiva. Noticias summarias das perseguiçoes da } \\
\text { missam de Cochinchina principiada, \& continuada pelos } \\
\text { Padres da Compahia de Jesv offerecidas pelos mesmos mis- } \\
\text { sionarios a el rey... (Lisboa, 1700). }\end{array}$ \\
\hline *3 tomos Ymagen de la & Franco SJ, Antonio (1662-1732). Imagen da virtude em o \\
\hline
\end{tabular}

${ }^{60}$ Originalmente publicado en francés, en París entre 1728-1731 en 7 volúmenes y continuado con otros 4 en 1753 y finalmente con 2 volúmenes en 1757. En el inventario-tasación de 1769 se concluye con esta obra, consignándose: "Yt. La Historia del Pueblo de Dios, prohibidos, por la Santa Ynquisicion, con otros varios Libritos, que son inutiles, no se tasaron” (f. 1162).

190 Silvana M. Lovay. Las bibliotecas de las estancias jesuíticas... 166-200. 
IHS. Antiguos Jesuitas en Iberoamérica ISSN: 2314-3908

\begin{tabular}{|c|c|}
\hline virtud & $\begin{array}{l}\text { noviciado da Companhia de Jesus na Corte de Lisboa } \\
\text { (Coimbra, 1717). } 3 \text { tomos }^{61} \text {. }\end{array}$ \\
\hline *Un tomo Fastos Lusitanos & $\begin{array}{l}\text { Barbosa Machado, Ignacio (1682-1772). Fastos policos e } \\
\text { militares da antigua e nova Lusitania en que se descreven as } \\
\text { acçoens memoraveis, que na Paz, e na guerra obraron os } \\
\text { Portugueses nas quatro partes do mundo (Lisboa, 1745). }\end{array}$ \\
\hline $\begin{array}{l}\text { *Censuras de la Historia de } \\
\text { la Compañía en la Provincia } \\
\text { del Paraguay }\end{array}$ & $\begin{array}{l}\text { Lozano SJ, Pedro (1697-1752). Historia de la Compañía de } \\
\text { Jesús en la Provincia del Paraguay (Madrid, 1754-1755). } 2 \\
\text { tomos }^{62} \text {. }\end{array}$ \\
\hline *2 tomos Villalobos & $\begin{array}{l}\text { Villalobos OFM, Enrique de (i?-1637). Svma de la teolo- } \\
\text { gia moral y canónica (Salamanca, 1628- } \\
\text { 1629/1646/1668/1672/1682) } 2 \text { tomos. }\end{array}$ \\
\hline Suma moral & $\begin{array}{l}\text { Torresilla OFMCap, Martin (1635-1709). Suma de todas } \\
\text { las materias morales arreglada a las condenaciones pontifi- } \\
\text { cias de Alejandro VII y Inocencio XI (Madrid, 1691-1696), } 2 \\
\text { tomos. }\end{array}$ \\
\hline $\begin{array}{l}* 5 \text { tomos de Haudri Niblio- } \\
\text { teca concionatoria }\end{array}$ & $\begin{array}{l}\text { Houdry SJ, Vicente (1631-1729). Bibliotheca concionato- } \\
\text { ria Ethices chistianae praecipua continens argumenta, ordi- } \\
\text { ne Alphabetico digesta (Lyon, } \\
\text { 1733/1742/1749/1750/1756/1764/1767) } 5 \text { tomos. }\end{array}$ \\
\hline $\begin{array}{l}\text { *Un tomo viejo, Breve rela- } \\
\text { ción de la Provincia de Chile }\end{array}$ & $\begin{array}{l}\text { Ovalle SJ, Alonso de (1601-1651). Historica relacion Del } \\
\text { Reyno de Chile Y de las misiones y ministerios que exercita } \\
\text { en la Compañía de Jesús... (Roma, 1646). }\end{array}$ \\
\hline *Otro braulina pontificia & $\begin{array}{l}\text { Marques SJ, Simão (1684-1766). Brasilia pontificia, sive, } \\
\text { Speciales facultates pontificiae, quae Brasiliae episcopis } \\
\text { conceduntur, et singulis decenniis renovantur, cum notatio- } \\
\text { nibus evulgatae, et in quatuor libros distributae (Lisboa, } \\
\text { 1749). }\end{array}$ \\
\hline *Otro Ludovico Blosio & $\begin{array}{l}\text { Blois OSB, François-Louis de (Ludovico Blosio) (1506- } \\
\text { 1566). Obras de Lvdovico Blosio abad leciense, monge de S. } \\
\text { Benito. Traducidas por Fray Gregorio de Alfaro, Monge y } \\
\text { Predicador de la misma orden... (París, } \\
\text { 1601/1608/1609/1625). }\end{array}$ \\
\hline *Otro Barradas in Evangelia & $\begin{array}{l}\text { Barradas SJ, Sebastian (1543-1615). Commentariorvm in } \\
\text { concordiam et Historiam qvatro Evangelistaum (Coimbra- } \\
\text { Lyón, 1599-1612) } 4 \text { Tomos. }\end{array}$ \\
\hline
\end{tabular}

${ }^{61}$ El P. Franco escribió además Imagem da virtude em o Noviciado... de Évora (Lisboa, 1714) en un tomo e Imagem da virtude... de Coimbra (Évora-Coímbra, 1719) en dos tomos. Solo el mencionado arriba se editó en tres tomos.

${ }^{62}$ Con este título también podría ser Nicolás del Techo SJ (1611-1685). Historia Provinciae Paraquariae Societatis Iesu (Lieja, 1673). Pero en esta obra no figura censura. Es más posible que sea la obra de Lozano, donde en el tomo 1, además de licencias y aprobaciones, cuenta con la "censura" del P. Joseph de la Guarda SJ.

191 Silvana M. Lovay. Las bibliotecas de las estancias jesuíticas... 166-200. 
IHS. Antiguos Jesuitas en Iberoamérica ISSN: 2314-3908

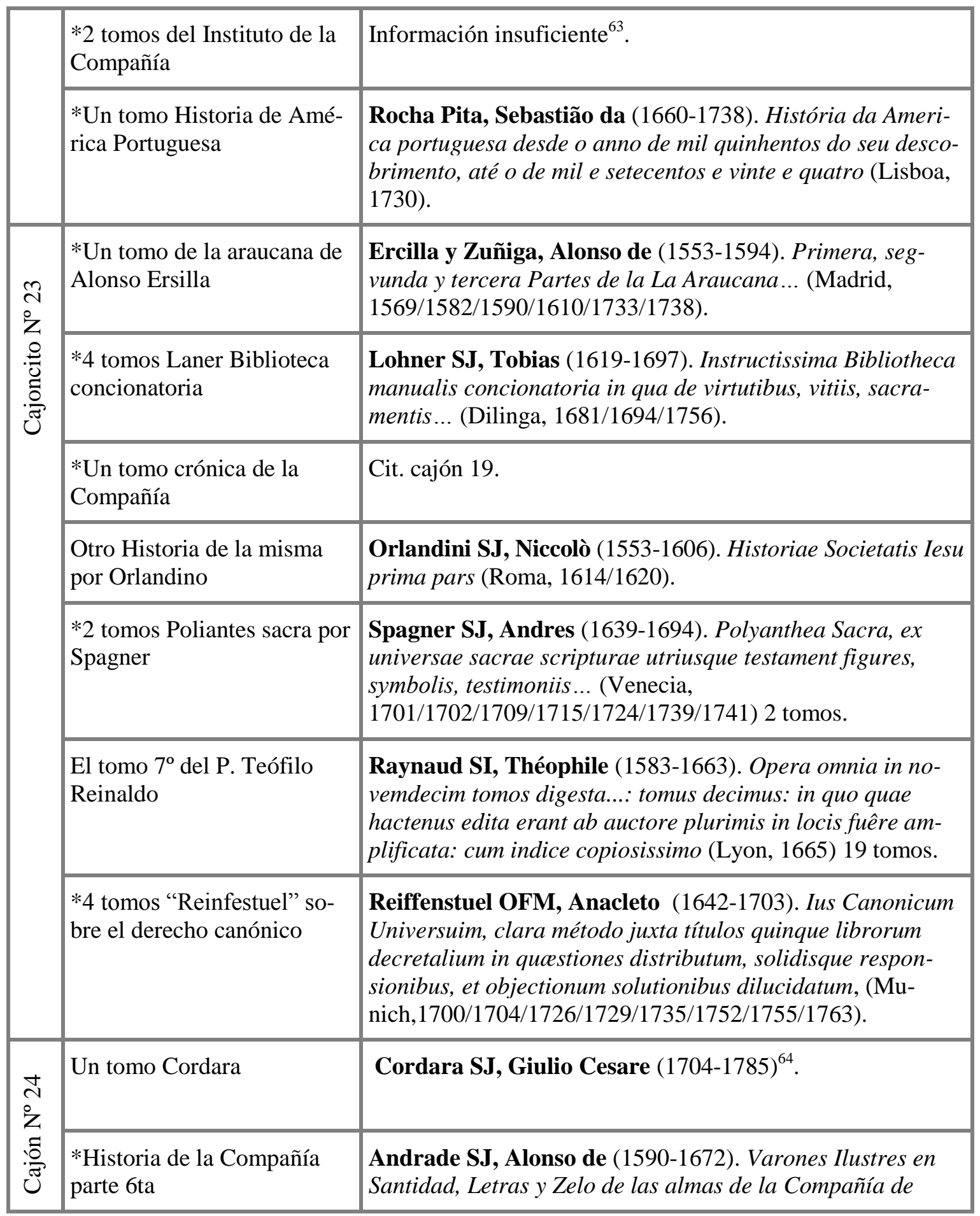

${ }^{63}$ Podrían ser 1- Ribadeneira SJ, Pedro (1526-1611). Tratado en el qual se da razón del Instituto de la religión de la Compañía de Jesús (Madrid, 1605). 2-Bartoli SJ, Danielo (1605-1685). Della vita e dell'Istituto di S. Ignazio fondatore della Compagnia di Giesu (Roma, 1650). 3-Ortiz SJ, Lorenzo (1632-1695). Origen y Institvto de la Compañía de Iesvs en la vida de San Ignacio de Loyola... (Sevilla, 1679).

${ }^{64}$ El P. Cordara publicó entre 1737 y 1750, tres obras. De las cuales dos, son de un solo tomo $1-L$. Sectani, Q. fil., de tota graeculorum huius aetatis litteratura ad Gaium Salmorium sermones quatuor. Accessere quaedam M. Philscardi; enarrationes (Ginebra, 1737) y Relazione della vita e martirio del Venerabil Padre Ignazio de Azevedo... (Roma, 1743). De dos tomos Historiae Societatis Jesu pars sexta complectens res gestas sub Mutio Vitellescho (Roma, 1750-1859).

192 Silvana M. Lovay. Las bibliotecas de las estancias jesuíticas... 166-200. 
IHS. Antiguos Jesuitas en Iberoamérica ISSN: 2314-3908

Vol. 5 no 2

julio-diciembre 2017

\begin{tabular}{|c|c|}
\hline & Jesús (Madrid, 1667) ${ }^{65}$. \\
\hline $\begin{array}{l}* \text { Otro tomo Ligorio in In- } \\
\text { dias }\end{array}$ & Información insuficiente ${ }^{66}$. \\
\hline $\begin{array}{l}\text { *Un tomo tesoro de la len- } \\
\text { gua castellana }\end{array}$ & $\begin{array}{l}\text { Covarrubias, Sebastián de (1539-1613). Tesoro de la leng- } \\
\text { vua castellana, o española (Madrid, 1611/1673). }\end{array}$ \\
\hline 2 tomos Elos Sanctorum & $\begin{array}{l}\text { Villegas, Alonso de (1533-1603). Flos sanctorum nuevo y } \\
\text { historia general de la vida y hechos de Jesu Christo y de } \\
\text { todos los santos de que reza y haze fiesta la Iglesia Catholi- } \\
\text { ca (Zaragoza, 1580/1582). }\end{array}$ \\
\hline $\begin{array}{l}* \text { El } 3^{\circ} \text { tomo de Fr. Luis de } \\
\text { Granada }\end{array}$ & Información insuficiente ${ }^{67}$. \\
\hline $\begin{array}{l}* 6 \text { tomos Diccionario de la } \\
\text { lengua castellana }\end{array}$ & $\begin{array}{l}\text { Real Academia Española. (1713-). Diccionario de la len- } \\
\text { gua castellana, en se explica el verdadero sentido de las } \\
\text { voces, su naturaleza y calidad con las phrases o modos de } \\
\text { hablar, los proverbios o refranes, y otras cosas convenientes } \\
\text { al uso de la lengua... (Madrid, 1726-1739) } 6 \text { volúmenes. S }\end{array}$ \\
\hline $\begin{array}{l}* 2 \text { tomos historia de Portu- } \\
\text { gal restaurada }\end{array}$ & $\begin{array}{l}\text { Meneses, Luís de, conde da Ericeira (1632-1690). Historia } \\
\text { de Portugal restaurado, em que se da noticia das mais glo- } \\
\text { riosas acções assim políticas, como militares, que obrárã̃ } \\
\text { os Portuguezes na restauraçaõ de Portugal, desde o anno de } \\
\text { 1662, até ao anno de 1668. (Lisboa, 1759) } 4 \text { tomos. }\end{array}$ \\
\hline $\begin{array}{l}\text { *Un tomo Historia de la } \\
\text { Compañía en Portugal }\end{array}$ & $\begin{array}{l}\text { Teles SJ, Baltasar (1596-1675). Chronica da Companhia de } \\
\text { Iesvs na Provincia de Portvgal e do qve fizeram, nas conqvis- } \\
\text { tas d'este Reyno... (Lisboa, 1635/1647) } 2 \text { tomos. }\end{array}$ \\
\hline $\begin{array}{l}\text { *Un Tomo Teatro eclesiásti- } \\
\text { co de las Iglesias de Indias }\end{array}$ & $\begin{array}{l}\text { González Dávila SJ, Gil (1577-1658). Teatro eclesiastico } \\
\text { de la primitiva iglesia de las Indias Occidentales : vidas de } \\
\text { sus Arzobispos, obispos y cosas memorables de sus sedes... } \\
\text { (Madrid, 1649-1655) } 2 \text { tomos. }\end{array}$ \\
\hline $\begin{array}{l}\text { *Un tomo ribadeneira 1era y } \\
2 \text { da parte }\end{array}$ & $\begin{array}{l}\text { Ribadeneira SJ, Pedro de (1527-1611). Tratado de la tribu- } \\
\text { lacion, repartido en dos libros. En el primero se trata de las } \\
\text { tribulaciones particulares: y en el segundo de las generales }\end{array}$ \\
\hline
\end{tabular}

\footnotetext{
${ }^{65}$ Luego de los cuatro tomos que se imprimieran del P. Nieremberg entre 1643 y 1647 en conmemoración al primer siglo de la vida de la institución y con el fallecimiento del autor en 1658, continuó el trabajo emprendido su discípulo y compañero Alonso de Anfrade SJ. De tal manera que entre 1666 y 1667 completa con dos tomos más la que fue considerada en su tiempo una verdadera enciclopedia de la "cotidiana santidad jesuita", conteniendo un total de 525 biografías.

${ }^{66}$ En el inventario de 1769 se da el nombre de Alphonso, confirmando que se trata de San Alfonso María de Ligorio (1696-1787). Pero no podemos identificar alguna obra que trate de su paso por las Indias pues nunca estuvo en América y menos una de sus 111 títulos conocidos.

${ }^{67}$ Pueden ser: Granada OP, fray Luis (1504-1588). 1-Tertius tomus concionum de tempore, quae a Pascha dominicae Resurrectionis ad sextum usque Sacratissimi Corporis Christi habentur (Olysippone, 1576) 2-Tercera parte de la Introduccion del Symbolo de la Fe: que trata del mysterio de nuestra redempcion, en la qual ... por lumbre de razon se declara, quan conveniente medio aya sido este que la divina bondad y sabiduria escogio para la salud del linage humano (Salamanca, 1583).
}

193 Silvana M. Lovay. Las bibliotecas de las estancias jesuíticas... 166-200. 
IHS. Antiguos Jesuitas en Iberoamérica ISSN: 2314-3908

\begin{tabular}{|c|c|}
\hline & que Dios nos embia, y del remedio dellas... (Madrid, 1598). \\
\hline $\begin{array}{l}\text { Uno de la historia del nuevo } \\
\text { reino de Granada }\end{array}$ & $\begin{array}{l}\text { Cassani SJ, José (1673-1750). Historia de la provincia de } \\
\text { la Compañia de Jesus del Nuevo Reyno de Granada en la } \\
\text { America, descripcion y relacion exacta de sus gloriosas } \\
\text { missiones en el reyno... (Madrid, 1741). }\end{array}$ \\
\hline $\begin{array}{l}\text { *Uno Discursos historiales } \\
\text { por el P. Juan Burgos }\end{array}$ & $\begin{array}{l}\text { Burgos SJ, Juan de (1594-1670). Discvrsos historiales } \\
\text { panegyricos de las glorias de la Serenissima Reyna de los } \\
\text { Angeles de sv Sagrada Casa de Loreto, adornos de Escritu- } \\
\text { ra Sacra, y Santos Padres a la Historia Lavretana, que es- } \\
\text { crivio el Padre Horacio Tvrcelino... (Madrid, 1671). }\end{array}$ \\
\hline *2 tomos Pláticas caraventes & $\begin{array}{l}\text { Carabantes OFMCap, José de (1628-1694). Platicas do- } \\
\text { minicales, y lecciones doctrinales de las cosas mas essencia- } \\
\text { les, sobre los evangelios de las dominicas de todo el año, } \\
\text { para desempeño de párrocos y aprovechamiento de feligre- } \\
\text { ses (Madrid, 1704/1717) } 2 \text { Tomos. }\end{array}$ \\
\hline $\begin{array}{l}\text { Uno práctica universal de la } \\
\text { Zirugia }\end{array}$ & $\begin{array}{l}\text { Vico Genovese, Giovanni di (1450-1525). La prattica vni- } \\
\text { versale in cirvgia... (Venecia, 1556/1568/1576/1613/1669) } 2 \\
\text { tomos. }\end{array}$ \\
\hline $\begin{array}{l}\text { *Otro Instituciones quirúr- } \\
\text { gicas }\end{array}$ & Información insuficiente ${ }^{68}$. \\
\hline *Otro Glorias del sacerdocio & $\begin{array}{l}\text { Natale SJ, Antonio (1648-1663). Gloriae del Sacerdotio } \\
\text { rivelate a S. Brigida insieme co'suoi oblighi e pregiuditii } \\
\text { (Palermo, 1693/1696/1701/1716/1751/1752). }\end{array}$ \\
\hline $\begin{array}{l}\text { Otro expedición de la } \\
\text { Holanda contra Bahía de } \\
\text { Todos los Santos }\end{array}$ & $\begin{array}{l}\text { Relacion de la vitoria qve alcanzaron las armas catolicas en } \\
\text { la Baia de Todos los Santos, contra Olandeses, que fueron a } \\
\text { sitiar aquella Plaça en } 14 \text { de junio de } 1638 . . \text { (Madrid, } \\
\text { 1638/1639). }\end{array}$ \\
\hline 2 libritos Ejercicios & Cit. \\
\hline
\end{tabular}

\section{Inventario de 1769 (Obras no incluidas en el primer inventario)}

\begin{tabular}{|c|c|}
\hline $\begin{array}{l}\text { Yt. Quatro tomos intitulados } \\
\text { Annales del Ymperio, se } \\
\text { regularon por doze pesos, } \\
\text { importan... } 012\end{array}$ & $\begin{array}{l}\text { Tácito, Cornelio (58-117). Los cinco primeros libros de los } \\
\text { annales de Cornelio Tacito, que comienzan desde el din del } \\
\text { Imperio de Agusto, hasta la muerte de Tiberio...(Madrid, } \\
\text { 1615). }\end{array}$ \\
\hline $\begin{array}{l}\text { Yt. Dos Tomos de Baeza, } \\
\text { se tasaron en seis pesos } \\
006 \text {. }\end{array}$ & $\begin{array}{l}\text { Baeza SJ, Diego de (1552-1647). Sermones en todas las } \\
\text { fiestas de Nvestra Señora... (Valladolid, 1642). }\end{array}$ \\
\hline Yt. Un Tomo en folio Fray & Zamora OP, Alonso (1635-1717). Historia de la Provincia \\
\hline \multicolumn{2}{|c|}{$\begin{array}{l}{ }^{68} \text { Podrían ser 1-Mercado, Luis (1625-1611). Institvtiones chirvrgicae ivssv region factae pro chirvgis in } \\
\text { praxi examinadis...(Madrid, 1594). 2-Lorenz Heister (1683-1758). Institvtiones chirvrgicae in qvibvs } \\
\text { qvicqvid ad rem chirvrgicam pertinet...(Amsterdam, 1739/1740/1749) } 2 \text { tomos. }\end{array}$} \\
\hline
\end{tabular}

194 Silvana M. Lovay. Las bibliotecas de las estancias jesuíticas... 166-200. 


\begin{tabular}{|c|c|}
\hline $\begin{array}{l}\text { Alonso Zamora, se tazó en } \\
\text { dos pesos } 002 .\end{array}$ & $\begin{array}{l}\text { de San Antonino del Nuevo Reino de Granada (Barcelona, } \\
\text { 1701). }\end{array}$ \\
\hline $\begin{array}{l}\text { Yt. Dos tomos año christia- } \\
\text { no, que se tazaron por qua- } \\
\text { tro pesos } 004 .\end{array}$ & $\begin{array}{l}\text { Croiset SJ, Jean (1656-1738). L'année chrétienne : conte- } \\
\text { nant les messes des dimanches, fetes \& feries de toute } \\
\text { Pannée en latin et en François, avec L'explication des epi- } \\
\text { tres \& des evangiles, \& un abregé de la vie de Saints don } \\
\text { on fait l'office (Lyon, 1712-1720) }{ }^{69} .12 \text { volúmenes. }\end{array}$ \\
\hline $\begin{array}{l}\text { Yt. un tomo en folio, el } \\
\text { Padre Pablo Herlojio, se } \\
\text { tasó por tres pesos } \$ 003,00\end{array}$ & Información insuficiente. \\
\hline $\begin{array}{l}\text { Yt. cinco tomos en folio } \\
\text { Herrera, tasados por catorce } \\
\text { pesos } \$ 014,00\end{array}$ & $\begin{array}{l}\text { Herrera, Antonio de (1549-1626). Descripción de las In- } \\
\text { dias Occidentales (Madrid, 1601/1730) } 5 \text { tomos. }\end{array}$ \\
\hline $\begin{array}{l}\text { Yt. uno en folio, Rainazidi, } \\
\text { se tasó por tres pesos } \$ \\
003,00\end{array}$ & Información insuficiente $^{70}$. \\
\hline $\begin{array}{l}\text { Yt. un dicho el Padre Tole- } \\
\text { do, se tasó por dos pesos } \$ \\
002,00\end{array}$ & Información insuficiente ${ }^{71}$. \\
\hline $\begin{array}{l}\text { Yt. Diez y seis Tomos Ca- } \\
\text { lino, se tazaron por ocho } \\
\text { pesos.. } 008\end{array}$ & Información insuficiente ${ }^{72}$. \\
\hline $\begin{array}{l}\text { Yt. ocho tomos en Portu- } \\
\text { gués Gobea, se apreciaron } \\
\text { en dieciséis pesos } \$ 016,00\end{array}$ & Información insuficiente. \\
\hline $\begin{array}{l}\text { Yt. Sensura de Historias de } \\
\text { Don Nicolas Antonio, un } \\
\text { tomo, por quatro pesos... }\end{array}$ & $\begin{array}{l}\text { Antonio, Nicolás (1617-1684). Censura de historias fabulo- } \\
\text { sas: obra posthuma de Don Nicolas Antonio ...: van añadi- } \\
\text { das algunas cartas del mismo autor, y de otros eruditos (Va- } \\
\text { lencia, 1742). }\end{array}$ \\
\hline $\begin{array}{l}\text { Yt. Un tomo, intitulado el } \\
\text { Abulense en tres ps... } 003\end{array}$ & $\begin{array}{l}\text { Almonacid OCist, Joseph de (-1704). El Abvlense ilvstra- } \\
\text { do. Minas del oro de España descvbiertas en los escritos } \\
\text { del Illmo. Señor D. Alonso Tostado, Obispo que fue de Abi- } \\
\text { la... Madrid, } 1673 \text {. }\end{array}$ \\
\hline $\begin{array}{l}\text { Yt. Un Tomo, Hores suma- } \\
\text { runt, en dos pesos... }\end{array}$ & Información insuficiente. \\
\hline
\end{tabular}

${ }^{69}$ La obra fue traducida al castellano por el P. Isla SJ, José Francisco de (1703-1751) y publicada en Salamanca, entre 1753 y 1773.

${ }^{70}$ Podría ser Raicsani SJ, Jean (1670-1733), quien Sommervogel registra 11 obras.

${ }^{71}$ Podría ser el cardenal Toledo SJ, Francisco de (1532-1596), quien publicó una decena de obras.

${ }^{72}$ Posiblemente se refiera al jesuita Calino, que publicó Considerazioni e discorsi famigliari, e morali a comodo di chi voglia ogni giorno fissare il pensiero in qualche verità eterna, e ad uso de' reverendi parrochi dall' altare e de' direttori di congregazini, e di esercizi spirituali, en 11 tomos impresos en Venecia entre 1736 y 1754.

195 Silvana M. Lovay. Las bibliotecas de las estancias jesuíticas... 166-200. 


\begin{tabular}{|c|c|}
\hline $\begin{array}{l}\text { Yt. Dos tomos, Caravantes, } \\
\text { en seis pesos ...006 }\end{array}$ & Información insuficiente ${ }^{73}$. \\
\hline $\begin{array}{l}\text { Yt. Quatro tomos del Padre } \\
\text { Biba, se tasaron por seis } \\
\text { pesos... } 0006\end{array}$ & Información insuficiente. \\
\hline $\begin{array}{l}\text { Yt. Un tomo Joseph Mansi } \\
\text { en dos pesos ... } 002\end{array}$ & Información insuficiente. \\
\hline $\begin{array}{l}\text { Yt. uno en Alemán Alonso } \\
\text { Rodríguez en } \$ 001,00\end{array}$ & Rodríguez SJ, Alonso (1538-1616). \\
\hline $\begin{array}{l}\text { Yt. Uno missioneros de la } \\
\text { Compañía, en } 007\end{array}$ & Información insuficiente. \\
\hline $\begin{array}{l}\text { Yt. Seis Tomos Diccionario } \\
\text { histórico, se tazaron por } \\
\text { tres pesos... } 003\end{array}$ & Información insuficiente ${ }^{74}$. \\
\hline $\begin{array}{l}\text { Yt. uno dicho Instrucción } \\
\text { de enfermeros, en quatro } \\
\text { reales } \$ 000,04\end{array}$ & $\begin{array}{l}\text { Hijos de la congregación del venerable } \mathbf{P} \text {. Bernardino de } \\
\text { Obregón }{ }^{75} \text {. Instruccion de enfermeros, y modo de aplicar } \\
\text { los remedios, a todo genero de enfermedades y acudir a los } \\
\text { accidentes, que sobrevienen en ausencia de medicos (Ma- } \\
\text { drid, 1617/1625/1680/1728). }\end{array}$ \\
\hline $\begin{array}{l}\text { Yt. Reglas de la Compañía, } \\
\text { un tomo por dos reales } \$ \\
000,02\end{array}$ & $\begin{array}{l}\text { Loyola, San Ignacio (c1491-1556). Reglas de la Compañía } \\
\text { de Jesús y la Carta de obediencia de Nuestro Glorioso Pa- } \\
\text { dre San Ignacio, Formulas de los Votos, y documentos del } \\
\text { mismo Santo Padre (Sevilla, 1735/1751). }\end{array}$ \\
\hline $\begin{array}{l}\text { Yt. Una Biblia en tres pe- } \\
\text { sos... } 003\end{array}$ & Información insuficiente. \\
\hline $\begin{array}{l}\text { Yt. Un tomo Exorsismos } \\
\text { contra maleficios }\end{array}$ & Información insuficiente ${ }^{76}$. \\
\hline $\begin{array}{l}\text { Yt. un tomo, Católica Ce- } \\
\text { remonia, en dos reales } \$\end{array}$ & Información insuficiente. \\
\hline
\end{tabular}

\footnotetext{
${ }^{73}$ Carabantes OFMCap, José de (1628-1694). Dos obras de este autor contienen dos tomos: Remedios de pecadores... (Madrid, 1678), Platicas dominicales... (Madrid, 1717).

${ }^{74}$ En el primer inventario de 1767 no se lo menciona. Pueden ser la edición en castellano del famoso Luis Moréri (1643-1680) que apareció en 1753, aunque en 10 tomos, sobre la base del Grand Dictionnaire historique, ou mélange curieux de l'histoire sacrée et profane. Lyon, 1674. También escribió un Diccionario histórico Pierre Bayle (1647-1706): Dictionnaire historique et critique, Rotterdam, 1695-1697, en cuatro volúmenes en francés.

${ }^{75}$ Bernardino de Obregón (1540-1599), fue caballero de la Orden de Santiago y en 1567 cambia su vida y se dedica a servir a enfermos pobres en el Hospital de la Corte. Al año siguiente formó una congregación que seguía las reglas de la Tercera de San Francisco. Fundó los hospitales de Santa Ana y el General de la Carrera de San Jerónimo en Madrid, entre otros, y al poco tiempo los "Enfermeros Obregones"

${ }^{76}$ Fue un género abundante entre los siglos XVI y XVII, periodo en el cual se escribieron muchos libros de autores como Bodin, Brognoli, Guaccio, Wier, Vanden Berge, Menghi, Sánchez, Thiers, Gómez Lodosa, Guazzo y otros muchos pero ninguno titula de esta manera, o al menos no conocemos este título.
}

196 Silvana M. Lovay. Las bibliotecas de las estancias jesuíticas... 166-200. 
IHS. Antiguos Jesuitas en Iberoamérica ISSN: 2314-3908

Vol. 5 no 2

julio-diciembre 2017

\begin{tabular}{|c|c|}
\hline 000,02 & \\
\hline $\begin{array}{l}\text { Yt. uno dicho Combibium } \\
\text { Divina y Amoris, se tasó } \\
\text { por cuatro reales. } \$ 000,04\end{array}$ & $\begin{array}{l}\text { Alloza SJ, Juan de (1618-1666). Convivium Divini Amoris, } \\
\text { Deus hominem amans, Christus in Eucharistiae Sacramento } \\
\text { latens, ut patefaciar Amoris (Lyon, 1665). }\end{array}$ \\
\hline $\begin{array}{l}\text { Yt. dos tomos Males male- } \\
\text { ficarum, en dos pesos } \$ \\
002,00\end{array}$ & $\begin{array}{l}\text { Kramer OP, Heinrich (c.1430-1505) y Sprenger OP, } \\
\text { Jacob (1435-1495). Mallevs Maleficarvm, maléficas et } \\
\text { earvm haeresim franea conterens (Estrasburgo, } \\
\text { 1486/1574/1669). }\end{array}$ \\
\hline $\begin{array}{l}\text { Yt. quatro en Alemán, en \$ } \\
000,03\end{array}$ & Información insuficiente. \\
\hline $\begin{array}{l}\text { Yt. doce tomos Delicias de } \\
\text { Francia, y Portugal en seis } \\
\text { pesos } \$ 006,00\end{array}$ & $\begin{array}{l}\text { Álvarez Colmenar, Juan (nn). Les delices de l'Espagne \& } \\
\text { du Portugal: où l'on voit une description exacte des antiqui- } \\
\text { tez, des provinces, des montagnes ... : de la réligion, des } \\
\text { moeurs des habitans, de leur fêtes ... (Lérida, 1707-1715) }\end{array}$ \\
\hline $\begin{array}{l}\text { Yt. un librito Vida del Pa- } \\
\text { dre Aguilar, por un real \$ } \\
000,01\end{array}$ & $\begin{array}{l}\text { Villagarcía SJ, Félix Antonio de (1687-1759). Carta del } \\
\text { Padre Feliz Antonio de Villagarcia, Vicerrector del Colegio } \\
\text { de la Compañía de Jesus de la Assumcion. Para los Padres } \\
\text { Superiores de la Provincia del Paraguay. Sobre la vida, } \\
\text { virtudes y muerte del P. Jayme de Aguilar, Provincial (Li- } \\
\text { ma, 1749). }\end{array}$ \\
\hline $\begin{array}{l}\text { Yt. Quatro Tomos de la } \\
\text { Recopilacion deIndias, se } \\
\text { tasaron por diez y seis pe- } \\
\text { sos...0.16 }\end{array}$ & $\begin{array}{l}\text { Antonio de León Pinelo (1595-1660) Juan de Solórzano } \\
\text { Pereira (1575-1655). Recopilacon de leyes de los reynos de } \\
\text { las Indias mandadas a imprimir, y pvblicar por la magestad } \\
\text { católica del rey don Carlos II Nvestro Señor. Madrid, } 1681 .\end{array}$ \\
\hline $\begin{array}{l}\text { Yt. uno la Cruz aligerada, } \\
\text { en cuatro reales } \$ 000,04\end{array}$ & $\begin{array}{l}\text { Pinamonti SJ, Giovanni Pietro (1632-1703). La cruz ali- } \\
\text { gerada, o motivos para confortarse en las tribulaciones : } \\
\text { espuestos en siete consideraciones, distribuidas por cada } \\
\text { día de la semana por el P. Juan Pedro de Pinamonti ; tra- } \\
\text { ducido del italiano al español por el P. de Gamiz (Barcelo- } \\
\text { na, 1738). }\end{array}$ \\
\hline $\begin{array}{l}\text { Yt. Contentus Mundi, en } \\
\text { cuatro reales } \$ 000,04\end{array}$ & $\begin{array}{l}\text { Kempis CRSA, Tomás de (1380-1471). De Contemptu } \\
\text { mundi Libel lusvalde utilis... (Toledo, } \\
1512 / 1526 / 1566 / 1572)^{78} \text {. }\end{array}$ \\
\hline Yt. uno Puerto Mariano, en & Información insuficiente ${ }^{79}$. \\
\hline
\end{tabular}

\footnotetext{
${ }^{77} \mathrm{Al}$ estar escrito en francés, el tasador debe haberse equivocado con el título. Álvarez de Colmenar se lo conoce como un historiador del siglo XVIII que escribió los Anales de España y Portugal y Delicias de España y Portugal. Esta última tuvo una edición en Lerida de 5 tomos en 1707 y otra en seis tomos en 1715. Pero en realidad se cree que es el pseudónimo del editor holandés Pieter van der Aa (1659-1733) o quizás de algún autor francés.

${ }^{78}$ Posiblemente haya sido la versión en castellano (Menosprecio del mundo) traducida por Jerónimo de Ripalda SJ (1535-1618) y publicado en 1576 y 1587, y luego Juan Eusebio Nieremberg SJ (1595-1658). Se trata del libro la De Imitatione Christi, clásico de la literatura mística conocido por Kempis Contemptu mundi, derivado del título del primer capítulo.
}

197 Silvana M. Lovay. Las bibliotecas de las estancias jesuíticas... 166-200. 


\begin{tabular}{|l|l|l|}
\hline & cuatro reales \$000,04 & \\
\cline { 2 - 3 } & $\begin{array}{l}\text { Yt. El Angélico Joven, en } \\
\text { un real \$ 000,01 }\end{array}$ & $\begin{array}{l}\text { Capelluchi SJ, Juan (¿?). El angelico joven San Luis Gon- } \\
\text { zaga, propuestp por modelo de una exemplar, y santa vida } \\
\text { en algunas consideraciones (Barcelona, 1737/1755). }\end{array}$ \\
\hline
\end{tabular}

\section{Conclusiones}

Nos quedan muchos interrogantes, como por ejemplo saber si originalmente la biblioteca contaba, como en los colegios, con un prefecto; si tenía índice o catálogo y si había realmente un espacio especialmente asignado o, como era común, los libros se encontraban dispersos en las habitaciones de los jesuitas. Con seguridad creemos que la colección no se formó con libros de "descartes" del colegio, porque había obras de primer nivel y algunas que el colegio no poseía.

La desintegración de la biblioteca comenzó con los mismos inventarios que realizó la Junta de Temporalidades. El método empleado no fue el sugerido por el conde de Aranda, pero al menos hay en ellos una aproximación que nos abre una idea global y genérica del conocimiento intelectual de los religiosos. Claramente no era una biblioteca que tenía una finalidad pedagógica como en los colegios.

El volumen de libros inventariados en la estancia de Santa Catalina fue de importancia, pues ese mismo caudal podía ostentar tranquilamente un Colegio Menor, como alguno de América o España. Esto nos indica el compromiso intelectual de sus moradores, en su mayoría visitantes esporádicos.

Es una evidente biblioteca religiosa, aunque apenas se amplía en otras temáticas que no sean la predominante teología moral y la dogmática.

El conocimiento de esta biblioteca, aislada del resto, no permite asumir alguna conclusión, pero evidencia la preferida lectura de obras de moral como en el resto de las bibliotecas jesuíticas. Pues la casuísitica constituyó una base del apoyo pastoral como única salida teológica del momento. También interesa la teología espiritual y oratoria que cultivaron los jesuitas, pues el púlpito era como una escuela de predicación, cerrando así las premisas de obras necesarias para el púlpito, el confesionario y la cátedra. Los temas hagiográficos y marianos no están ausentes, como se habían establecido en las normas tridentinas. Un caso atípico es el libro prohibido, la Medulla del P. Busenbaum, del que había dos ejemplares, aunque creemos que los jesuitas desconocían su prohibición, menos aún los tasadores que bien podrían haberla señalado como de "doctrina peligrosa”.

Ya explicamos que se hizo un inventario en 1767 que se desconoce su paradero, pero que en 1771 lo copiaron. La aparente finalidad de ubicarlos en cajones sería para trasladarlos al Colegio Máximo, aunque al completarse el inventario con su tasación, dos años después, queda evidente que los libros no fueron trasladados y no se habla más de los cajones, en un inventario que tiene incluso otro orden de clasificación. En el inventario de 1769, donde creíamos evidente la desaparición de libros, por el contrario aparecen obras que no se habían inventariado anteriormente, pero en este nuevo inven-

\footnotetext{
${ }^{79}$ Posiblemente Maurice O'Fihely, en latín: Maurice de Portu OF (1460-1513). Teólogo y arzobispo irlandés, escribió varias obras.
}

198 Silvana M. Lovay. Las bibliotecas de las estancias jesuíticas... 166-200. 
tario faltaron una importante suma de títulos que reafirma la hipótesis del destino de los mismos.

\section{Referencias}

Aguilar Piñal, F. (1986). Bibliografía de autores españoles del siglo XVIII, Madrid: Consejo Superior de Investigaciones Científicas-Instituto de Filología. 8 tomos.

Archivo Histórico de la Universidad Nacional de Córdoba, Caja 3, A 1, № 11, Legajo 5, septiembre de 1769. Orden a Don Fernando Fabro Superintendente de Temporalidades, se ejecute tasación general de todos los bienes secuestrados a los jesuitas expulsos, en la ciudad de Córdoba y las Estancias adyacentes de este Colegio Máximo. (Antes en Archivo General de la Nación (Argentina), Temporalidades de Córdoba 1768 - 1769, Sala IX 21-9-2).

Astorgano Abajo, A. (2007). Lorenzo Hervas y Panduro, Biblioteca jesuítico-española (1759-1799). Estudio introductorio, edición crítica y notas... Madrid: Libris.

Backer, A. y A. de (1853-1861). Bibliothéque des éscivains de la Compagnie de Jésus ou notices bibliographiques... Lieja: imprimie de L. Grandmont-Donders. 7 tomos.

Barrabino, M. (2014). Memoriales de los Provinciales para los domicilios de Córdoba. 2 da parte. IHS. Antiguos jesuitas en Iberoamérica, 2(2), pp. 222-253. Recuperado de: http://ciecs-conicet.gob.ar/revistas/index.php/ihs/article/view/50/52

Biblioteca Mayor (1943). Catálogo de la librería jesuítica Tomo .1 A-F. Córdoba: Universidad Nacional (catálogo confeccionado por Juan Carlos Ferrer, Enrique Ferrer Vieyra, Felipe Obeid y Alejandro Sipowicz).

Cabrera, Ms. P. (1930). La antigua Biblioteca Jesuítica de Córdoba, Revista de la Universidad Nacional de Córdoba, julio-Agosto, pp. 175 a 216.

Colección General de Providencias hasta aqui tomadas por el gobierno sobre el extrañamiento y ocupacion de temporalidades de los regulares de la Compañia... Parte primera (1767). Madrid: Imprenta del Consejo.

Fraschini, A. F. (2003). Index librorvm Bibliothecae Collegii Maximi CordVbensis Societatis Jesv 1757. Edición crítica, filológica y biobibliográfica. Buenos Aires. Recuperado

de: http://www.bn.gov.ar/descargas/pnbc/estudios/pnbc_estudio5_indexlibrorum.pdf

Furlong SJ, G. (1993). Arte en el Río de la Plata 1530-1810. Buenos Aires: Tea. (1944). Bibliotecas argentinas durante la dominación hispánica. Buenos Aires: Editorial Huarpes.

Gorzalczany, M. A. y Olmos Gaona, A. (2006). La biblioteca jesuítica de Asunción. Buenos Aires: TGS Industria Gráfica.

López Piñero, J. M. et.al. (1987). Bibliographia medica hispana, 1475-1950. Valencia: Instituto de estudios documentales e históricos sobre la ciencia.

López Piñero, J. M. y Bujosa Homar, F. (1981). Los impresos científicos españoles de los siglos XV y XVI. Inventario, bibliometría y thesaurus. Valencia: Universidad de Valencia. 3 tomos.

199 Silvana M. Lovay. Las bibliotecas de las estancias jesuíticas... 166-200. 
Llamosas, E. (2000a). Las obras de la Biblioteca Jesuítica de Córdoba en poder de Fernando Fabro. Cuadernos de Historia, Academia Nacional de Derecho, № 9 , Córdoba.

(2000b). El Index Librorum Bibliothecae Collegii Maximi Cordubensis Societatis Jesu. En Aspell, M. y Page, C. A. (comp.) (2000). La biblioteca jesuítica de la Universidad Nacional de Córdoba. Córdoba: Universidad Nacional de Córdoba.

Martínez Villada (1919). Notas sobre la cultura cordobesa en la época colonial". Revista de la Universidad Nacional de Córdoba. IV(9-10), pp. 162-199.

Mateo Ripoll, Verónica (2002). Las bibliotecas de la Compañía de Jesús: el colegio de Orihuela. En: Enrique Giménez López (coord.), Y en el tercero perecerán: gloria, caída y exilio de los jesuitas españoles en el $s$. XVIII estudios en homenaje a P. Miquel Batllori i Munné. Alicante: Servicio de Publicaciones de la Universidad de Alicante, pp. 49-70.

Miguel Alonso, Aurora (1998). La organización de las bibliotecas de la Compañía de Jesús: un estudio de su evolución a partir de repertorios jesuitas. Trabajos de la Asociación Española de Bibliografía, II Madrid: Asociación Española de Bibliografía, pp. 77-100.

Núñez, C. (1980). La Estancia de Santa Catalina. Córdoba: Biffignandi.

O’Neill, C. y Domínguez, J. M. (directores) (2001). Diccionario Histórico de la Compañía de Jesús. Biográfico-Temático. Madrid/Roma: Universidad Pontificia de Comillas/Institutum Historicum SI. 4 tomos.

Page, C. A. (2011). Relatos del exilio. Memorias de los jesuitas expulsos de la antigua provincia del Paraguay. Asunción: Servilibro.

(2013). “Las cartas de los generales Tirso González y Miguel Ángel Tamburini para la provincia del Paraguay". IHS. Antiguos jesuitas en Iberoamérica, $\begin{array}{llllll}\text { Vol. } & 1 & \mathrm{~N}^{\circ} & 1 & \text { Recuperado } & \text { de: }\end{array}$ conicet.gob.ar/revistas/index.php/ihs/article/view/12

Palau y Dulcet, A. (1948-1987). Manual del librero hispano-americano: inventario bibliográfico de la producción científica y literaria de España y de la América Latina desde la invención de la imprenta hasta nuestro días, con el valor comercial de todos los artículos descritos. (segunda edición) Barcelona, 35 vols.

Paucke SJ, F. (2010). Hacia allá y para acá (memorias). Santa Fe: Ministerio de Innovación y Cultura.

Regulae Praefecti Bibliothecae (1620). Paris: Imprimerie D. Dumoulin Et Cie. Recuperado de: http://digicol.lib.depaul.edu/cdm/ref/collection/p15448coll3/id/4569

Sommervogel SI, C. (1890-1960). Bibliothéque de la Compagnie de Jésus. Bruselas/Madrid. 12 tomos.

Torre Revello, J. (1940). El libro, la imprenta y el periodismo en América la dominación española. Buenos Aires: Peuser.

Uriarte SJ, J. E. (1904-1916). Catálogo razonado de obras anónimas y seudónimas de autores de la Compañía de Jesús pertenecientes á la antigua asistencia española: con un apéndice de otras de los mismos, dignas de especial estudio bibliográfico. Madrid: Est. Tipográfico sucesores de Rivadeneira. 5 tomos. 